\title{
Fundamental Pyrolysis Studies
}

Thomas A. Milne

Robert J. Evans

Michael N. Soltys

March 1983

To be presented at the 15th Biomass Thermochemical Conversion Contractors Review Meeting Atlanta, Georgia 16-17 March 1983

Prepared Under Task No. 1303.00/1572.00

WPA No. 876

Contract No. B-C5848-A-Q/B-F0409-A-Q

Solar Energy Research Institute

A Division of Midwest Research Institute

1617 Cole Boulevard

Golden, Colorado 80401

Prepared for the U.S. Department of Energy Contract No. EG-?7-C-01-4042 


\section{NOTICE}

This report was prepared as an account of work sponsored by the United States Government. Neither the United States nor the United States Department of Energy, nor any of their employees, nor any of their contractors, subcontractors, or their employees, makes any warranty, express or implied, or assumes any legal liability or responsibility for the accuracy, completeness or usefulness of any information, apparatus, product or process disclosed, or represents that its use would not infringe privately owned rights. 
FUNDAMENT AL PYROLYSIS STUDIES

\author{
Thomas A. Milne \\ Robert J. Evans \\ Michael N. Soltys \\ Solar Energy Research Institute \\ 1617 Cole Boulevard, Golden, Colorado 80401
}

ABSTRACT

Progress on the direct mass spectrometric sampling of pyrolysis products from wood and its constituents is described for the period frm June, 1982 to February, 1983. A brief summary, and references to detailed reports, of the qualitative demonstration of our approach to the study of the separated processes of primary and secondary pyrolysis is presented. Improvements and additions to the pyrolysis and data acquisition systems are discussed and typical results shown. Chief of these are a heated-grid pyrolysis system for controlled primary pyrolysis and a sheathed-flame arrangement for secondary cracking studies. Qualitative results of the secondary cracking of cellulose, lignin, and wood are shown as are comparisons with the literature for the pyrolysis spectra of cellulose, lignin, and levoglucosan. "Fingerprints" for a number of materials are shown, with spectra taken under carefully controlled conditions so that sensitivity calibrations for different compounds, now being determined, can be applied.

INTRODUCTION

The goal of these studies is to determine, in molecular detail, the chemistry and kinetics of the primary and secondary pyrolysis processes for biomass and its constituents. To accomplish this under realistic pyrolysis conditions, we are coupling several pyrolysis heat transfer methods with a sampling system-mass spectrometer detector that permits real-time sampling and rapid quenching from ambient hot environments, while preserving reactive and condensible 
species for nearly universal detection by positive-ion mass spectroscopy.

Work in FY82 on the system and its qualitative performance has been described in two quarterly reports $(1,2)$ and a paper presented at the 14th Biomass Thermochemical Contractor's Review Meeting(3). An overall review of progress to date is contained in two papers accepted for publication in the Journal of Analytical and Applied Pyrolysis $(4,5)$ and a paper prepared for the International symposium on Fundamentals of Thermochemical Biomass Conversion $(6,7)$.

These publications present a wealth of detail on the design and qualitative performance of the pyrolysis and detection systems, with the conclusion that the chosen approach is well-suited to provide unique information about the details of pyrolysis under extreme conditions of rapid heating and unusual environments. Primary and secondary reactions can be followed over the temperature range from low temperature to $3000^{\circ} \mathrm{C}$, on the millisecond time scale. Pulsed pyrolysis can be carried out with samples in the 1-10 mg range as well as with much larger samples. Heating schemes used to date include the burnt-gas region of $\mathrm{Ar}-\mathrm{H}_{2}-\mathrm{O}_{2}$ or $\mathrm{He}-\mathrm{H}_{2}-\mathrm{O}_{2}$ flames; $\mathrm{Cal}$-rod $^{\mathrm{m}}$-heated inert gases ( $\mathrm{Ar}$, He, others if desired); and resistance heated grids. The sampling system is quite well suited to coupling with radiation heated surfaces (laser, solar collectors, arc) but these are not yet available in our laboratory.

In the period since the last report $(3)$, we have cleaned and made changes in the systems, and developed several techniques, all in preparation for the current phase of quantitative studies. This report describes these activities, a few results of parametric studles on cellulose, lignin and wood, and the first results from the application of several new techniques. A complementary study of the detailed organic mechanisms of cellulose pyrolysis is being carried out, using the same apparatus and techniques $(8)$ and funded by the SERI Director's Discretionary Fund. This study permits us to concentrate now on the quantitative mechanism of secondary pyrolysis of primary products from cellulose, lignin and wood. 
Results from the new work, where they provide information of direct relevance to existing studies, will be reported in this and subsequent progress reports. In the following sections we review instrumental developments followed by a discussion of recent experimental results and a comparison with the literature. The final section outlines planned studies for the remainder of FY 1983.

SYSTEM READINESS

System Cleaning

The free-jet sampler-mass spectrometer detection system, shown for reference in Fig. 1, had fallen into significant disrepair after a year and a half of steady use with a variety of hydrocarbons and biomass materials. The chief problem was a cumulatively massive increase in background contamination of the ion source and turbomolecular pump regions, such that even the phase-sensitive detection was hampered by unfavorable signal-to-noise ratios at certain masses. (This effect can be seen as positive-negative excursions on some of the mass spectra shown below. Noise is particularly bad in the vicinity of masses $47,70,80$, and 110.) This contamination became worse the longer either the turbomolecular pump or the mass spectrometer fon source were operated so that, finally, only about two hours of operating time were usable each day. Two sources of contamination were identified: oil from the turbomolecular pump that unaccountably backed up into the entire stage three chamber (see Fig. 1) and the expected long-term accumulation of pyrolysis tars and oils from the hundreds of samples inhaled through the molecular beam inlet.

In mid-August the system was completely disassembled for the following actions: a) a thorough vapor-degreasing of stage-three and the partially disassembled mass spectrometer; b) a thorough overhaul of the turbomolecular pump, with bearing replacement and substitution of a new, higher quality oil (Fomblin); c) solvent cleaning of the Edwards booster diffusion pump, prompted by the rather dirty state of the oil; d) a liquid $\mathrm{N}_{2}$ trap was interposed between the turbomolecular pump and the stage three cross. The system was back 


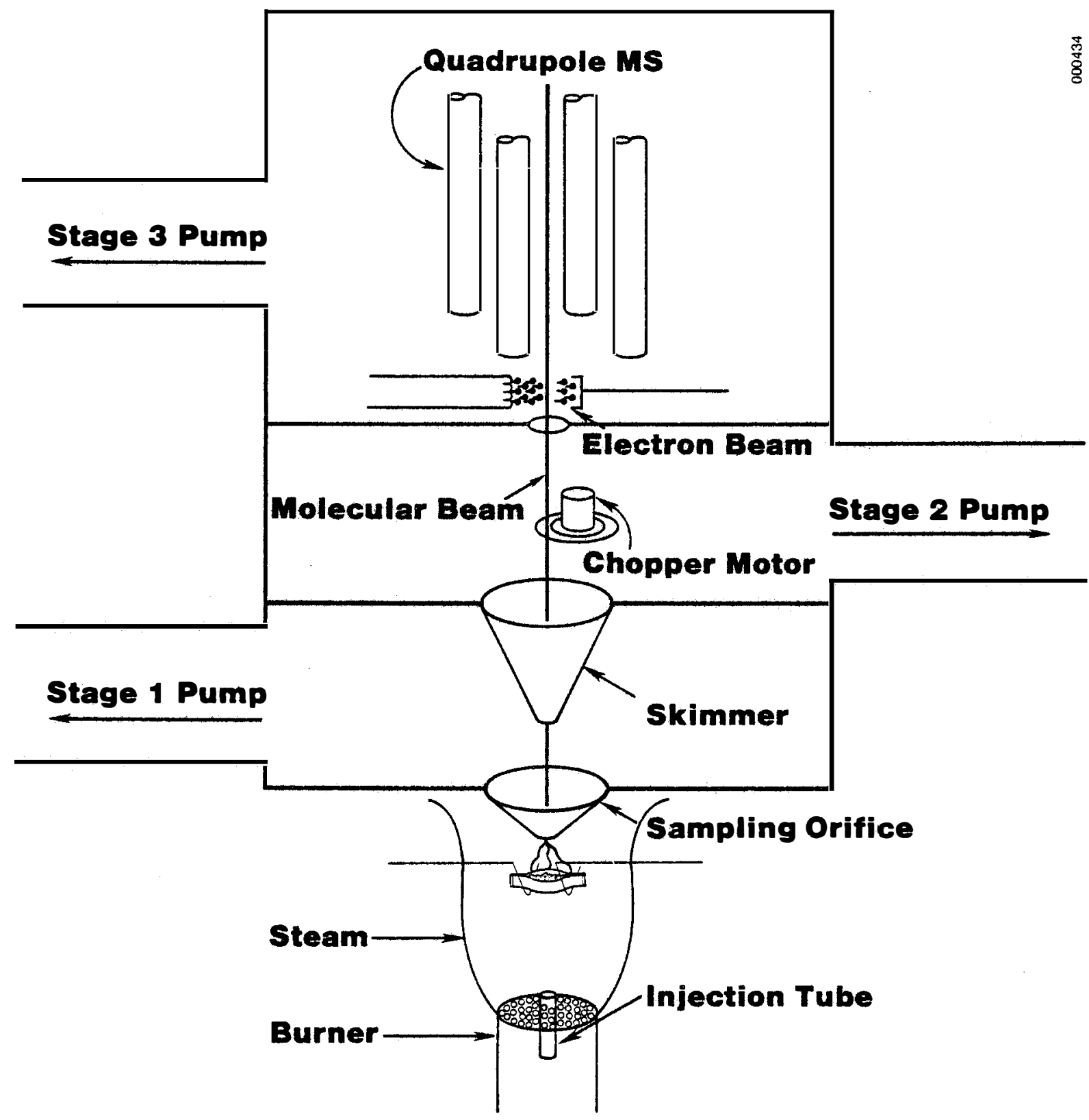

Figure 1. Molecular Beam Apparatus for Fast Biomass Pyrolysis 
in operation by mid-October, and showed a remarkable decrease in background levels of about two orders of magnitude. Furthermore, the system becomes cleaner with operation through the day, due to selfbaking of the ion-source.

Mass Spectrometer System Improvements

Three changes were made in the basic mass spectrometer system. First, the tungsten filament was replaced by a thoriated iridium filament, which operates at lower temperature and is more resistant to burnout. Second, a pre-amplifier, ion-counting package was added to permit direct ion counting. This capability is particularly useful for weak signals and for fast time response. As an example of the latter, the signature of a chopped, intense argon beam is displayed in Fig. 2. The chopping frequency is $1000 \mathrm{~Hz}$ and the time response is at the $\mu$ second or faster level. (The anomalous peaks and tails on what should be an essentially square wave probably represent a multiplier response effect caused by the intense ion beam from argon.)

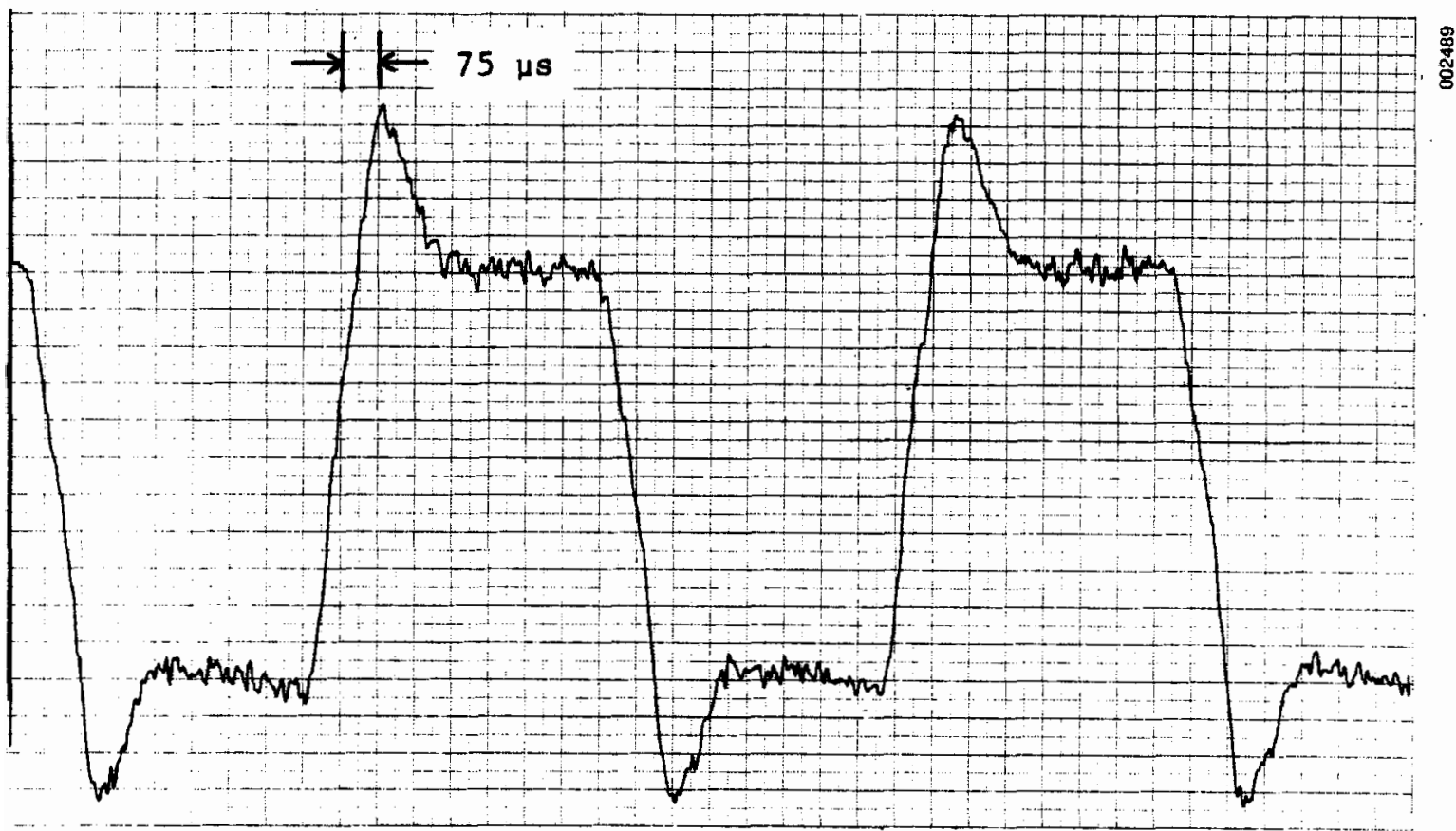

Figure 2. Chopped Molecular-Beam have Formed by Fast-Response, Direct Ion-Counting. 
A third addition to the mass spectrometer system is a 16 -channel, digitally controlled, peak switching system that allows the sequential monitoring of up to 16 ions during a pyrolysis event. Being designed, but not yet recelved, is a computer-based data acquisition system to record and process complete mass spectra as output from our phase-sensitive amplifier. Such a system will be needed as we enter the systematic, quantitative phase of work. Also available, but not yet tested, are the electronics to extend our mass range to 1500 amu to screen for very heavy oils and tars and an MS/MS system to enhance our ion identification abilities.

System For Quantitative Secondary Cracking Studies

In order to study the secondary cracking of the primary tars and oils observed from cellulose, lignin and wood, we have improved the flame system in several respects. Fig. 3 shows the new specimen holder and quartz spacers designed to confine the flame gases and prevent encroachment of surrounding air. The wire holders, for solid specimens like wood splints or rolled filter paper or for small boats for powders, are shown with spacings to hold a three-specimen array in a $2-\mathrm{cm} \times 2-\mathrm{cm}$ area. Such arrays will give higher pyrolysis vapor concentrations and will allow tests to be made of the importance of diffusion of vapors at extended secondary cracking distances. Previous tests have established that there is little cooling of the quartz-confined flame gases, at least over distances of $100 \mathrm{~cm}$. To observe secondary cracking as a function of distance the upper quartz cylinders are varied (e.g., 10, 20,40,80 mm) and the sampling cone is at or below the exit gas plane. First results with this system are shown below.

Heated -Grid System

The wire-mesh, resistance heated system, for forced, rapid heating of powders and thin specimens, was described earlier(3). This system, patterned closely after those used by the MIT group for coal and biomass studies ${ }^{(9)}$, has been tested both electrically and with the sampling system. Figures 4 and 5 show the heated-grid arrangement and the housing and sampling orifice plate arrangement. 


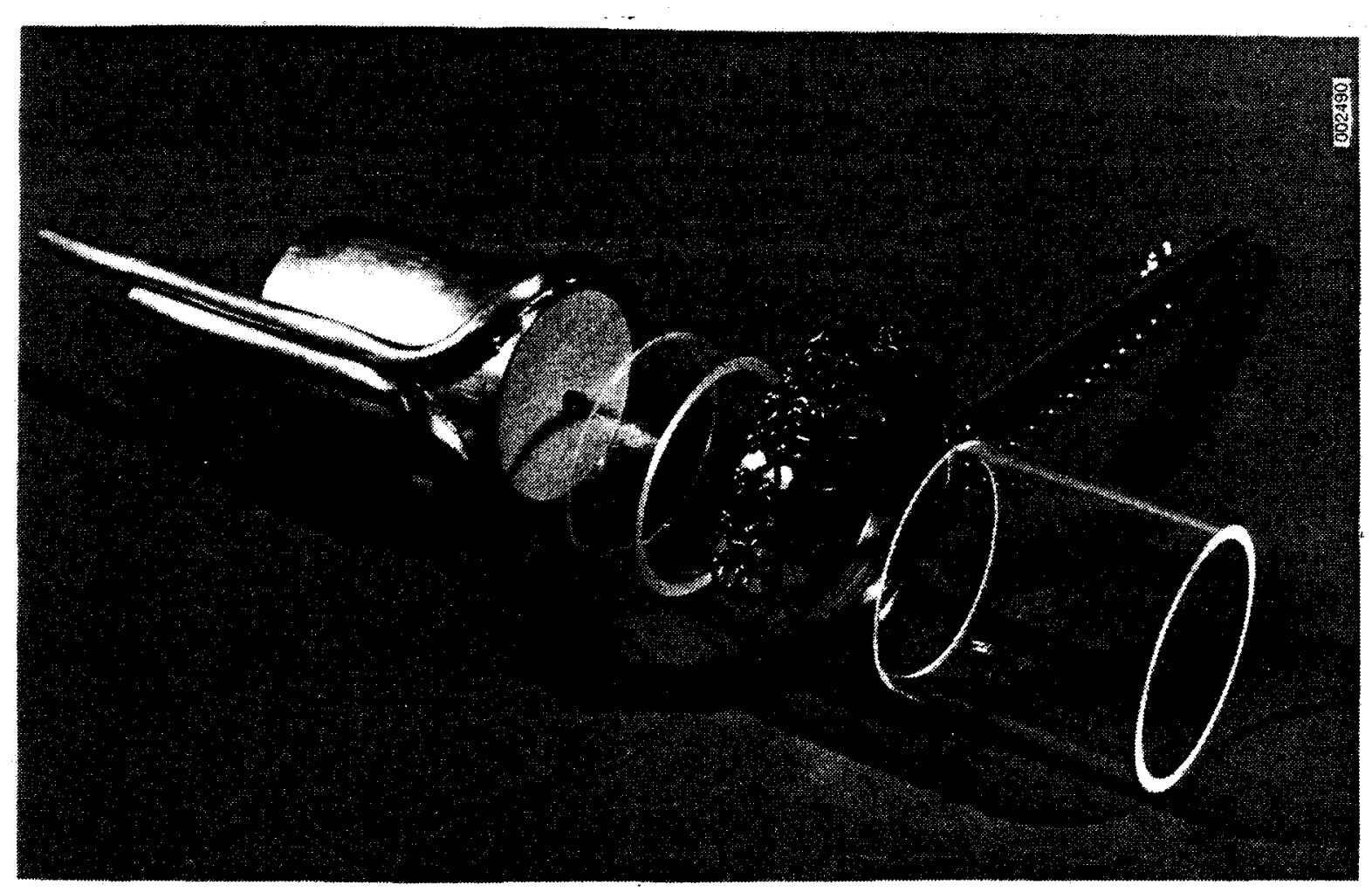

Figure 3. Photo of Sheathed Burner and New Sample Holder

In the preliminary experiments shown below, the grid was driven by the analog control unit, with no feedback control. In this mode, the control unit calls for a certain current as a step function, and for the same or a different current as a holding current, for a selected time. The heat up rate in this mode of operation is determined by a combination of the time-constant of the Vectrolm and the heat capacity of the grid system. An Apple computer, thermocouple feedback system is operational for closely controlling the actual heat up and holding profile when desired.

PRIMARY PYROLYSIS STUDIES

During the past year we have developed an operational set of parameters to permit both integrated scans over the entire pyrolysis wave and to observe the sequential evolution of up to 16 peaks through a pyrolysis event. With the sampling system placed at a few to $10 \mathrm{~mm}$ above the pyrolyzing surface, largely primary events are observed, even in surrounding $900^{\circ} \mathrm{C}$ steam/argon. 


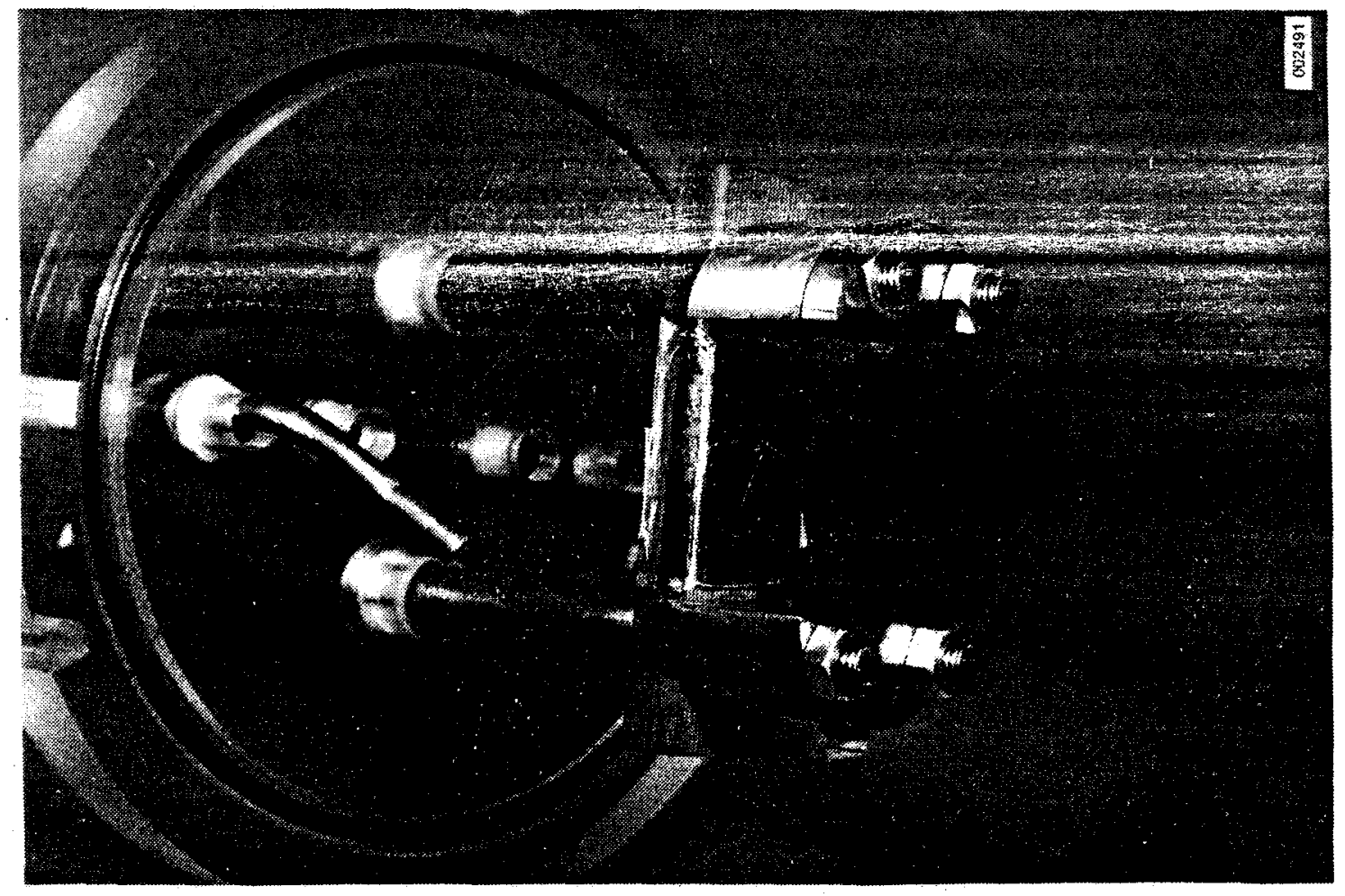

Figure 4. Photo of Grid Structure

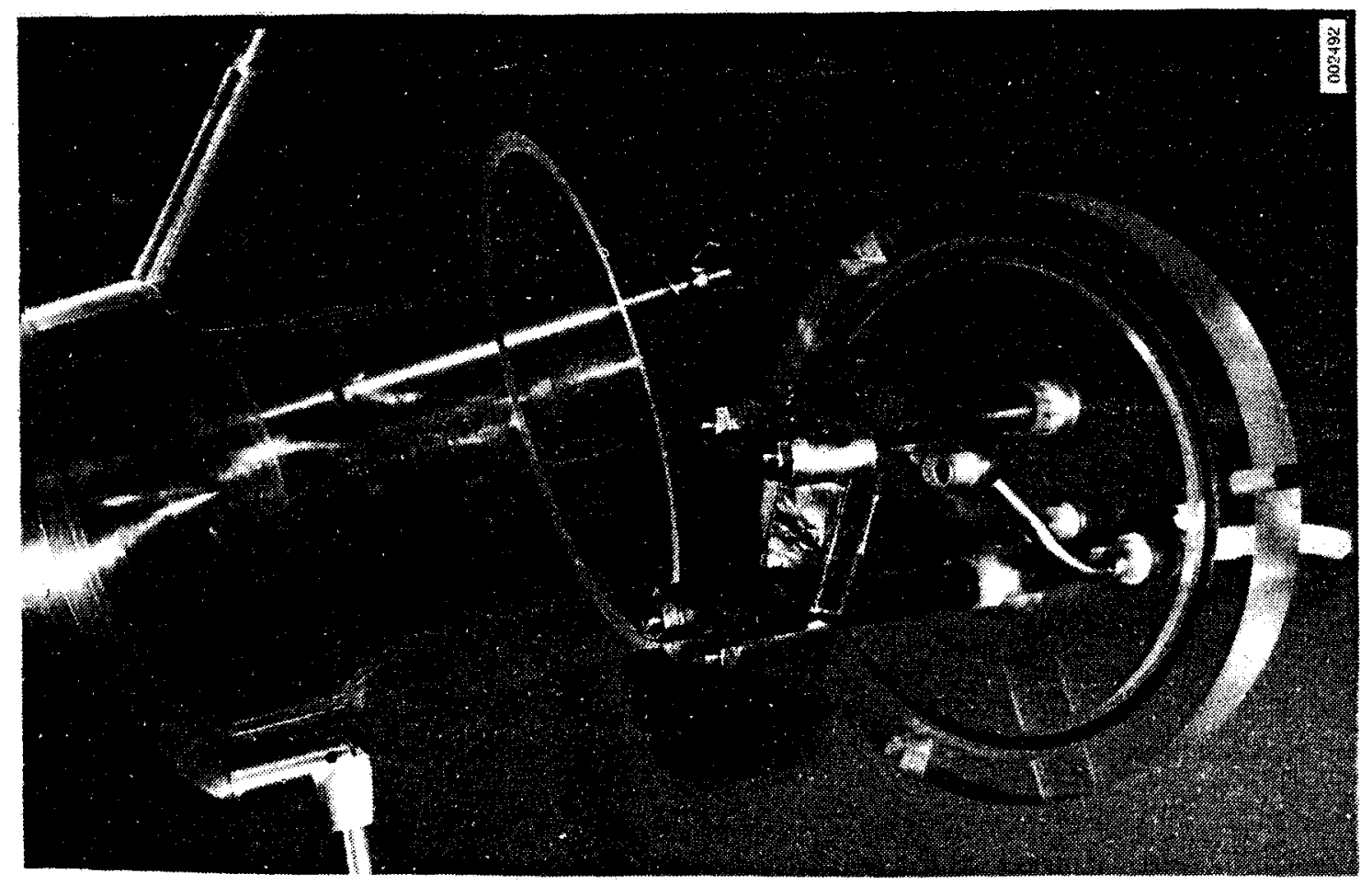

Figure 5. Assembly Photo of Heated Grid System 
The data acquisition and sensitivity characteristics are such that we are limited to 400 amu scans at a one-second repetition rate (with some loss in resolution). More frequent scans can be used over smaller mass ranges in a reciprocal trade-off (e.g., 40 am intervals could be scanned in $0.1 \mathrm{sec}$ ). Single-ion monitoring can be used to follow changes on the millisecond time scale, limited only by the time response of the phase-locked amplifier (present frequency of beam chopping is $1000 \mathrm{~Hz}$ ).

We have still not developed an optimum tuning for our quadrupole mass spectrometer to achieve both workable resolution and sensitivity and to faithfully transmit both heavy and 1 ight lons (e.g., $16^{+}$from methane and $162^{+}$from levoglucosan). In much of the data shown below, tuning was for high-mass transmission in the 60-220 mass range, with large discrimination against light gases. It is likely that two sets of experiments will have to be performed to quantitatively assess both high and low molecular-welght pyrolysis product behavior. Examples of the quality of spectra now being obtained are seen in the experiments described below.

Cellulose--Dependence on Several Parameters

In the quantitative study of the pyrolysis of cellulose, the initial question was whether the pyrolysis mass spectrum depended strongly on the type of cellulose, its physical form, the degree of crystallinity and polymerization, temperature, lonizing electron energy, quantity of sample, heating environment, and impurities. A large number of spectra were taken for cellulose under a variety of conditions, as reported in earlier progress reports $(1-3)$. The gen eral conclusion, though we did not have cellulose samples precisely characterized as to degree of crystallinity, degree of polymerization and nature of impurities, is that, for the heavier tars and oils at least, the primary product slates are quite similar over the range of parameters studied. As examples, Figs. 6-11 compare spectra (heavy masses emphasized) for: five types of cellulose at both high and low electron energy (Figs. 6 and 7); small vs. large specimens (Fig. 8); temperature of gaseous pyrolysis medium (Fig. 9); He vs. Ar as flame 


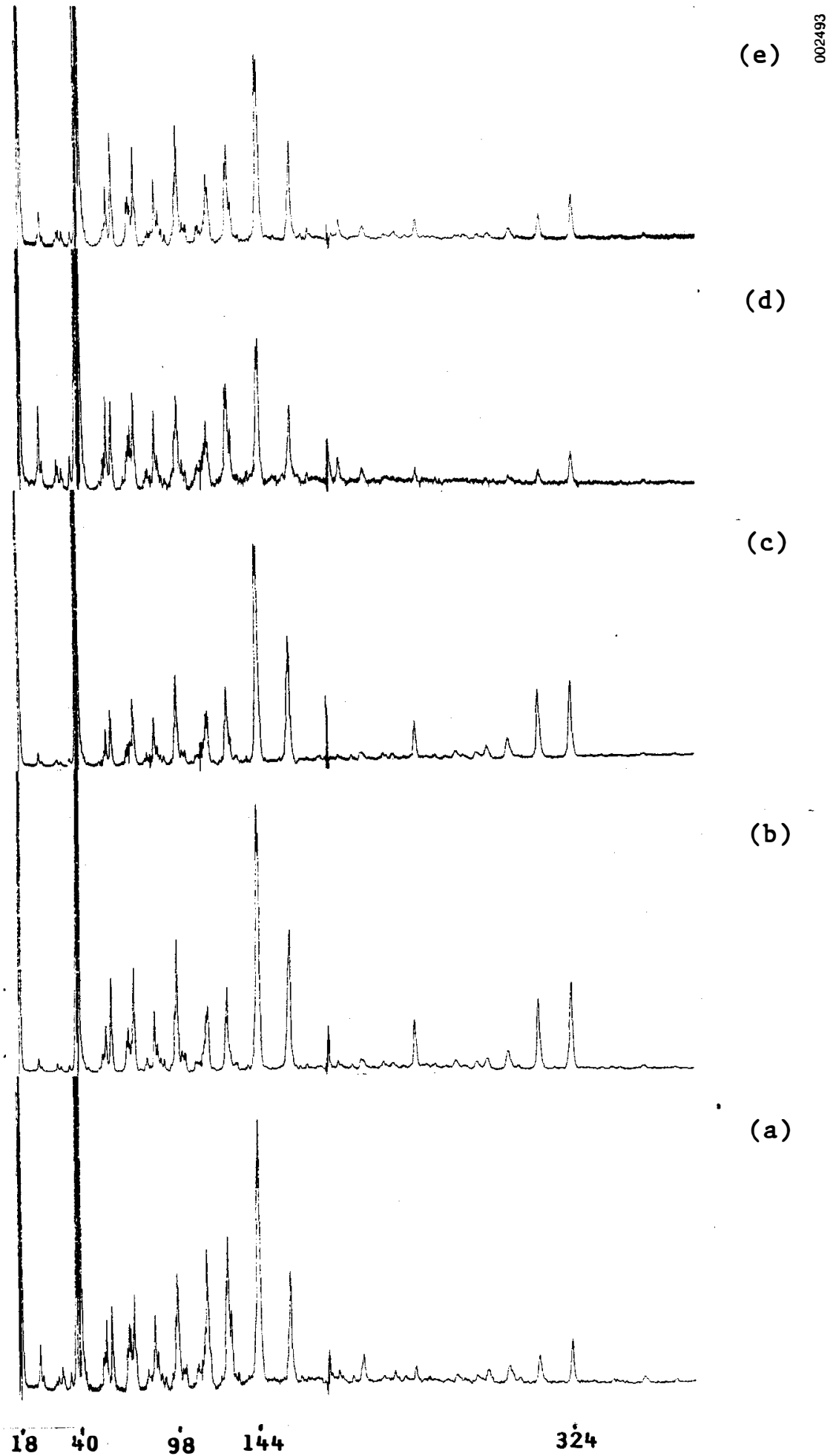

Figure 6. Primary Pyrolysis Mass Spectra of Five Different Specimens Heated in $900^{\circ} \mathrm{C} \mathrm{H}_{2} / \mathrm{O}_{2} \mathrm{Ar}$ Flame Gases; Electron Energy $50 \mathrm{eV}$. (a) filter paper (thin sheet); (b) cotton thread; (c) Sigma chemical amorphous powder; (d) Avicel crystalline powder, $90 \mu$; and (e) Avicel crystalline powder, $20 \mu$ (powders heated in small boats). 


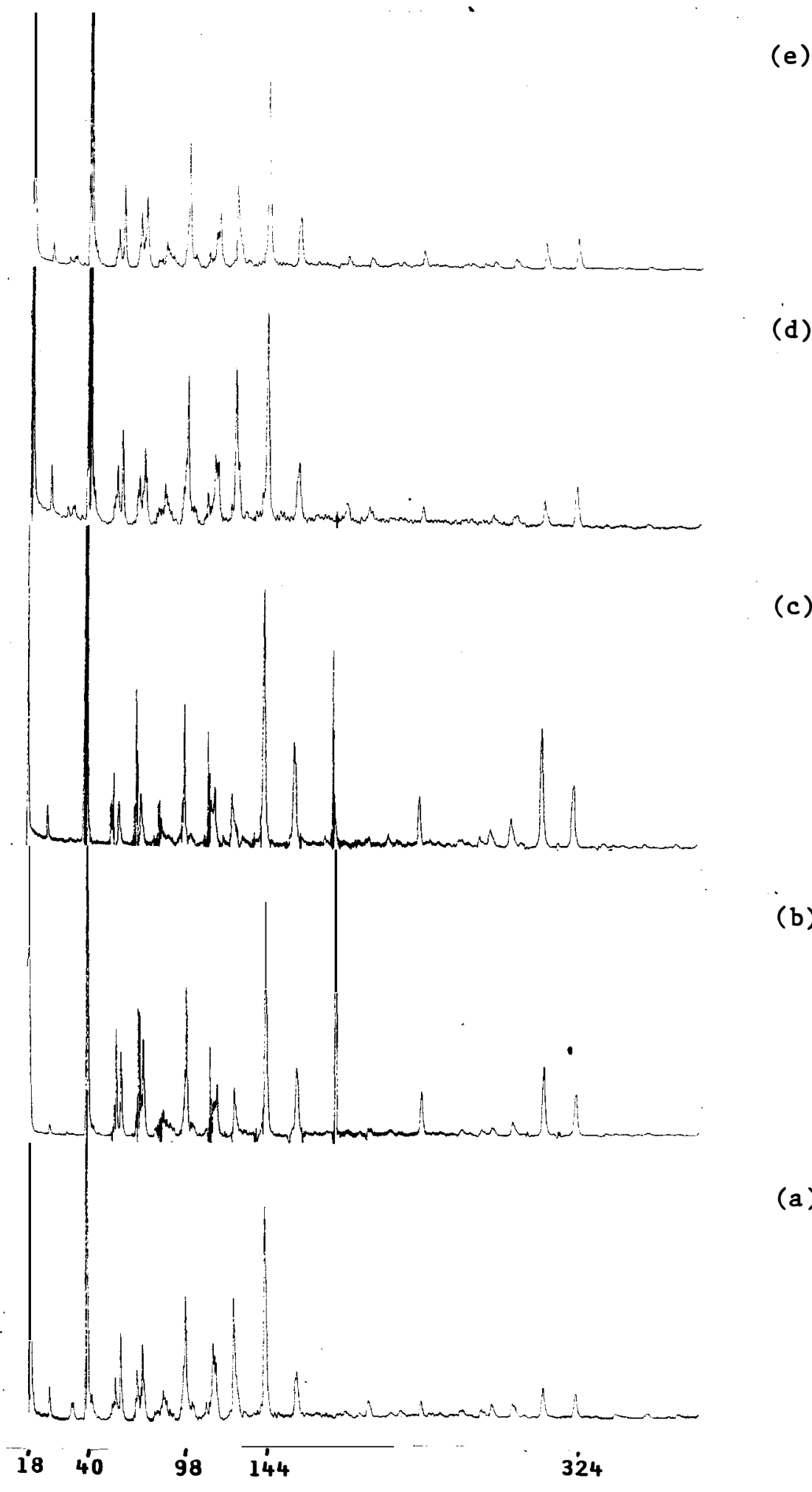

Pigure 7. Primary Pyrolysis Mass Spectra of Five Different Specimens Heated in $900^{\circ} \mathrm{C} \mathrm{H}_{2} / \mathrm{O}_{2} / \mathrm{Ar}$ Flame Gases; Electron Energy $-17 \mathrm{eV}$. (a) filter paper (thin sheet); (b) cotton thread; (c) Sigma chemical amorphous powder; (d) Avicel crystalline powder, $90 \mu$; and (e) Avicel crystalline powder, $20 \mu$ (powders heated in small boats). 

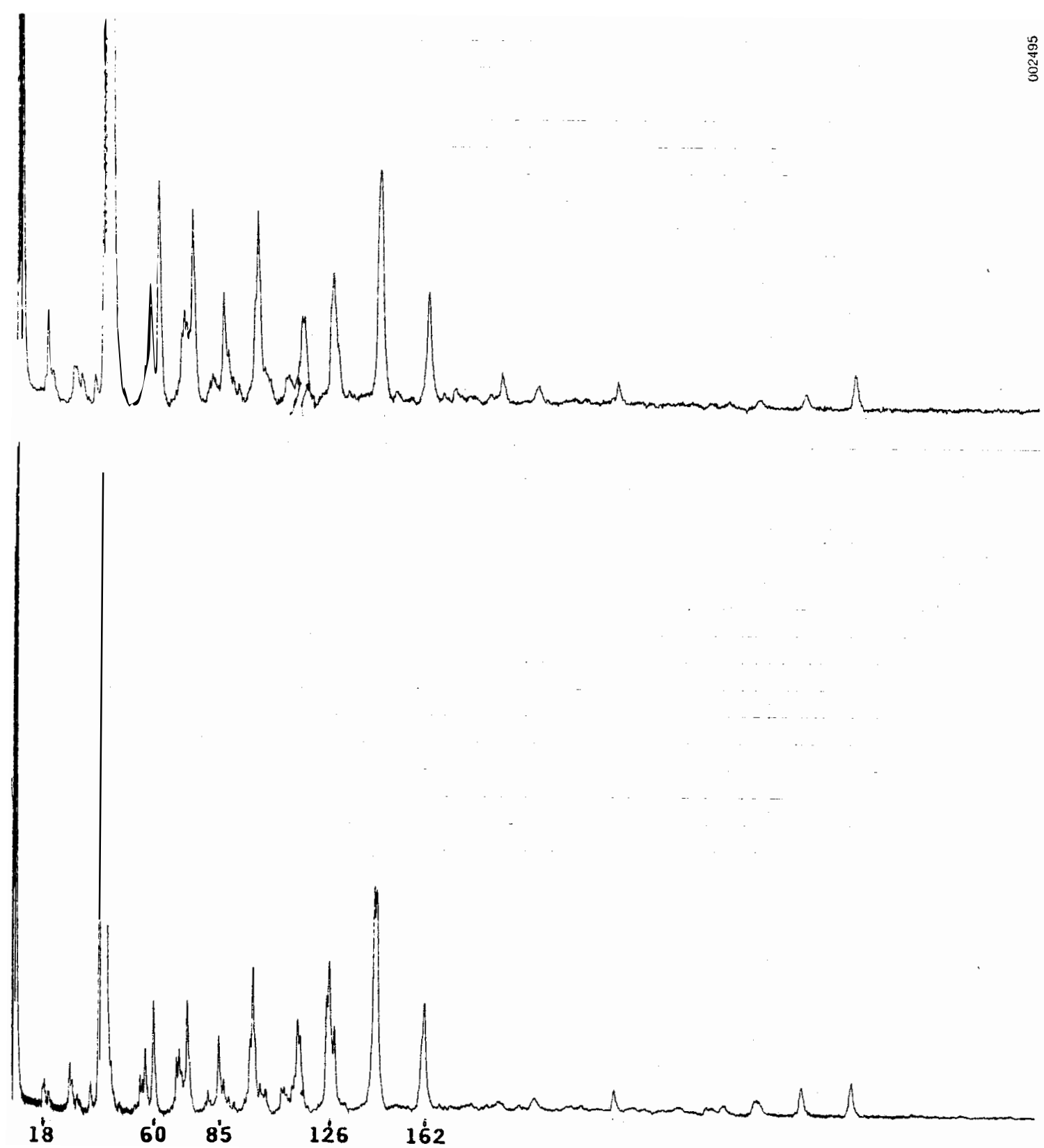

Figure 8. Comparison of $50 \mathrm{eV}$ Spectra of Small ( 17 mg) and Large ( )100 mg) Rolls of Filter Paper in $900^{\circ} \mathrm{C}$ Steam/Argon. Lower spectrum is for small specimen. 




Figure 9. Comparison of Cellulose Spectra in $900^{\circ} \mathrm{C}$ Steam/Argon (Upper) and in $450^{\circ} \mathrm{C}$ Hot Argon (Lower). 


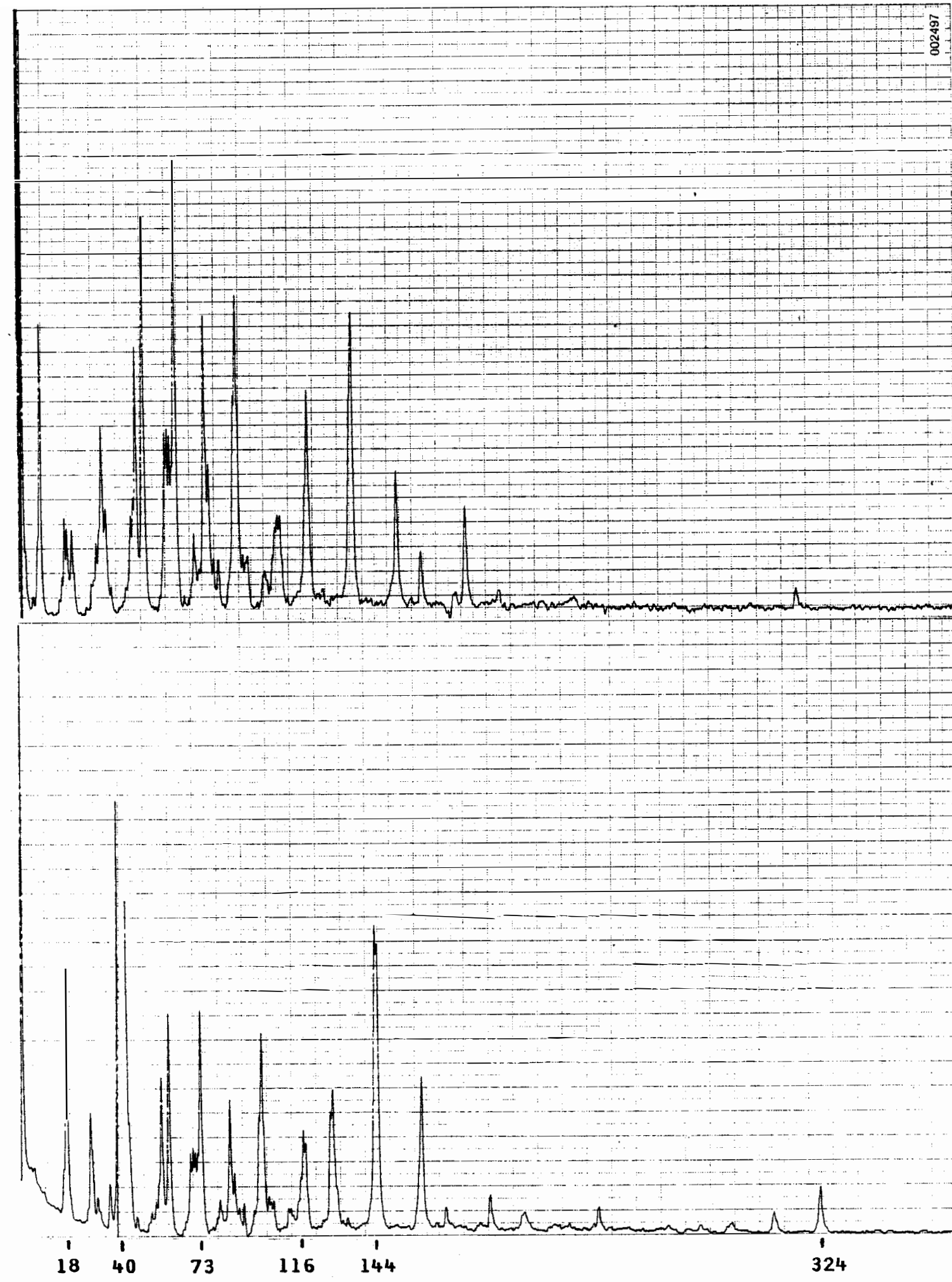

Figure 10. Comparison of Cellulose Pyrolysis Products then Heated in $\mathrm{He} / \mathrm{H}_{2} / \mathrm{O}_{2}$ (Upper) and $\mathrm{Ar} / \mathrm{B}_{2} / \mathrm{O}_{2}$ Flame (Lower). Electron Energy $50 \mathrm{eV}$. 

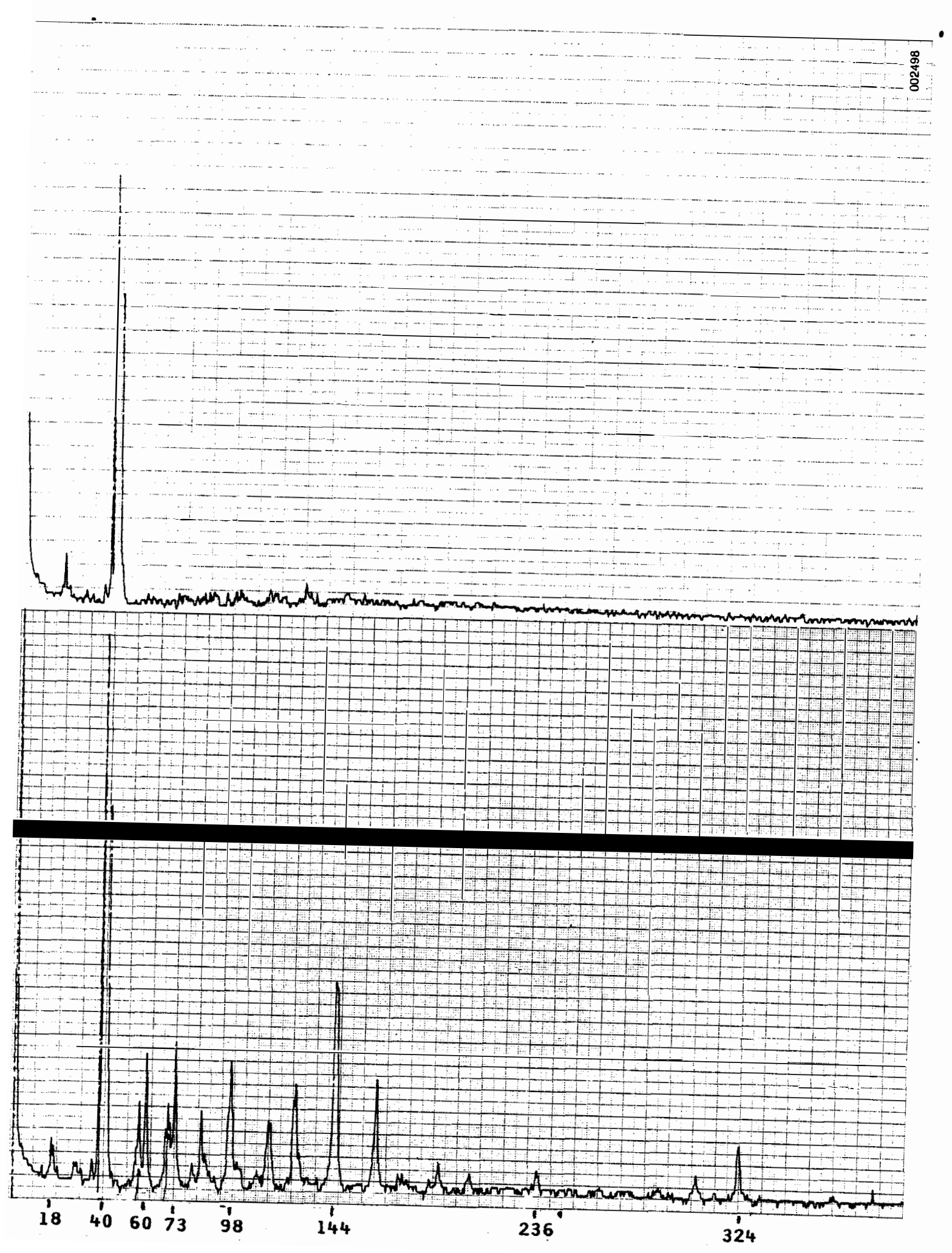
Figure 11. Effect of $1 \% \mathrm{~K}$ (from $\mathrm{R}_{2} \mathrm{CO}_{3}$ ) (Opper) on Pyrolysis Spectrum at Bigh
Masses of Cellulose ( $\mathrm{Filter}$ Paper) in $900^{\circ} \mathrm{C}$ Flame. Blectron
Energy $50 \mathrm{eV}$. 
gas diluent (Fig. 10); and the effect of $1 \% \mathrm{~K}$ (from $\mathrm{K}_{2} \mathrm{CO}_{3}$ ) added to filter paper (Fig. 11). Allowing for minor differences in mass spectrometer tuning, and noting the interference of background noise in some spectra, the spectra over this range of variation in samples and conditions are remarkably similar, with the exceptions of the $\mathrm{He} / \mathrm{H}_{2} / \mathrm{O}_{2}$ flame results and the $\mathrm{K}$-impurity. These latter spectra deserve more study. As shown in Fig. 12, the heat transfer from the helium diluted flame is much greater, even though the two burnt-gas regions are at virtually the same temperature. Whether the faster heating rate, the presence of secondary cracking, differences in mass separation effects, or some other effect is responsible for the small difference in He vs. Ar spectra is a matter of some interest. Heated-grid experiments, where the sample is in better thermal contact with the pyrolysis heat source, may shed light on the cause of the He/Ar difference. The effect of small amounts of $K$ is dramatic and is consistent with literature reports that even $0.1 \%$ alkali can profoundly alter pyrolysis of pure cellulose(10).

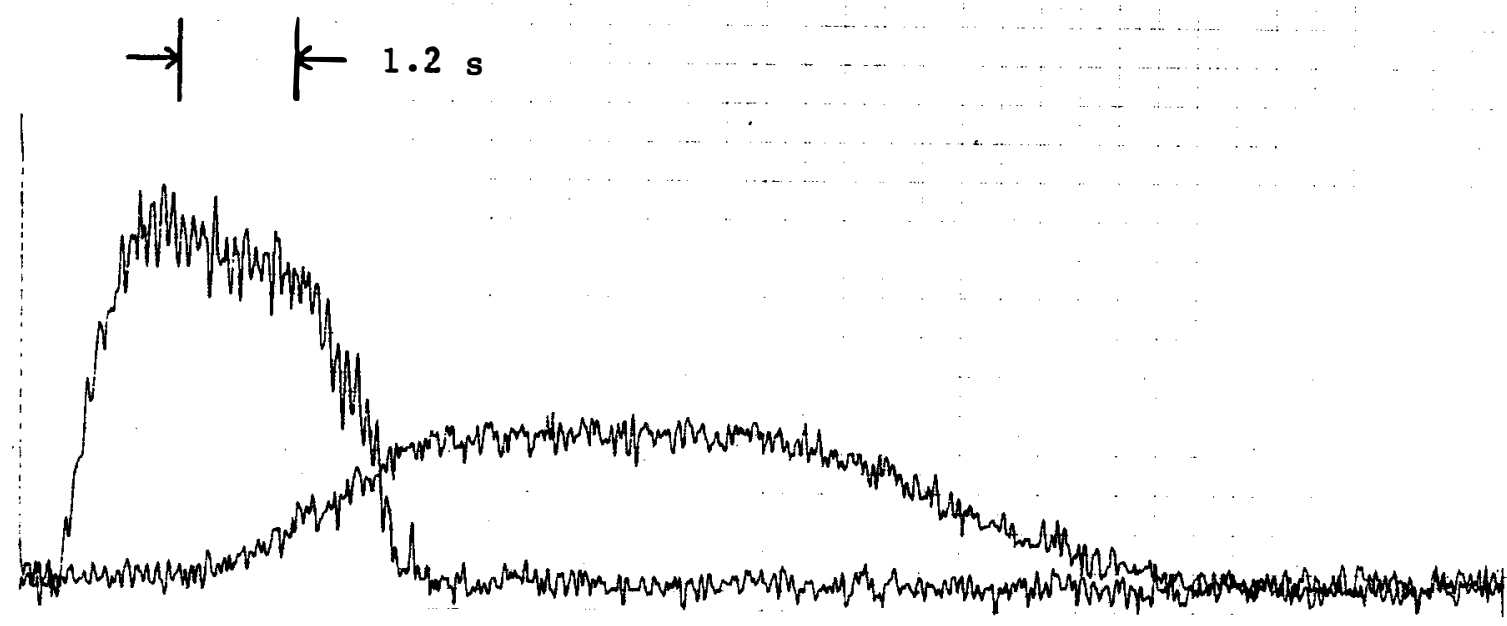

Figure 12. Pyrolysis Profiles from Cellulose $\left(60^{+}\right)$Heated in $\mathrm{He} / \mathrm{B}_{2} / \mathrm{O}_{2}$ and $\mathrm{Ar} / \mathrm{H}_{2} \mathrm{O}_{2}$ Flames of the Same Temperature. The helium flame profile is on the left. 
For the purposes of establishing the details of primary pyrolysis the differences shown in Figs. 6-11 may have significance and will be examined further in the work supported by the Director's discretionary funds $(8)$. To study the pathways and conditions for optimum yields of secondary products from primary tars and oils, the choice of cellulose form (as long as it is quite pure) would appear to be a matter of experimental convenience. The first quantitative studies of secondary cracking will probably use rolled strips of ashfree filter paper (Whatman 非40).

Cellulose and Lignin Spectra--Comparison with Literature

Two comparisons of our preliminary spectra with literature data are possible. First is a comparison of the types of ion peaks observed with prior chemical identification of tars and oils. In a previous report(11), identification of lons with precursors widely reported by others showed the reasonableness of the species observed under our conditions. Prominent in the suspected cellulose products are levoglucosan (162), 1,6-anhydro-3-deoxy- $\beta$-glucopyranose (144), levoglucosenone (126), 5 methyl-2-furaldehyde (110), furfurylalcohol (98), 1 -hydroxy-2-propanone $\left(74^{+}, 73^{+}\right.$?), 2 -butanol $\left(70^{+}\right)$, acetic acid and hydroxy acetadehyde $\left(60^{+}\right)$and methanol $\left(32^{+}\right)$. Prominent in lignin spectra are three series of ions; 94, 108, 122, 136, 150, 164, 178 . . for alkyl phenols; 124, 138, 152, 164, 180 . . . for monomethoxy phenols and 154,168,182, 196, 210 . . for dimethoxy phenols. Dihydroxy benzene at 110 is another identification. Wood (see below) shows peaks consonant with cellulose and lignin, plus two peaks, $96^{+}$and $114^{+}$, expected from the reported hemicellulose pyrolysis products 2 -furaldehyde and 3-hydroxy-2,2-penteno1,5 -lactone, respectively (12).

A second comparison is with the spectra reported in the analytical pyrolysis literature, where the heating of micrograms of material in high vacuum at temperature below $600^{\circ} \mathrm{C}$ is common. Such a comparison is shown for several 1iterature spectra(13-17) in Fig. 13. A discussion was given in a previous report ${ }^{(2)}$. The most striking feature of Fig. 13 is the relative lack of high-mass ions in 


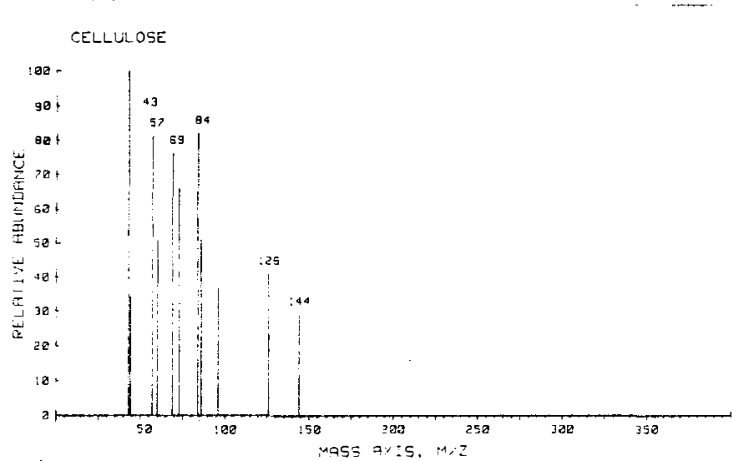

(d)

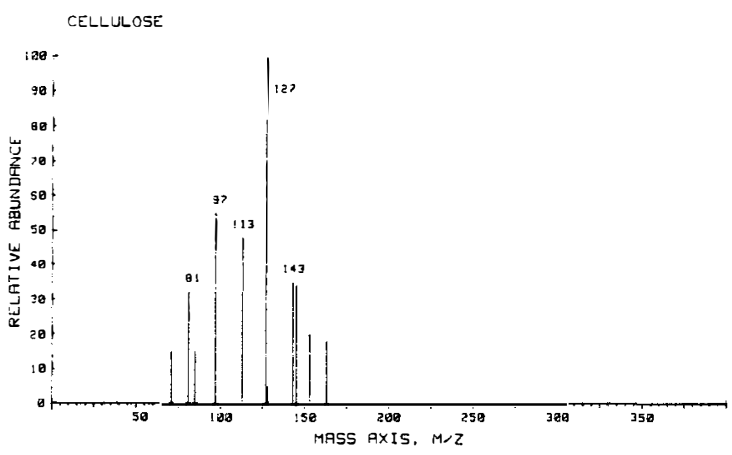

(c)

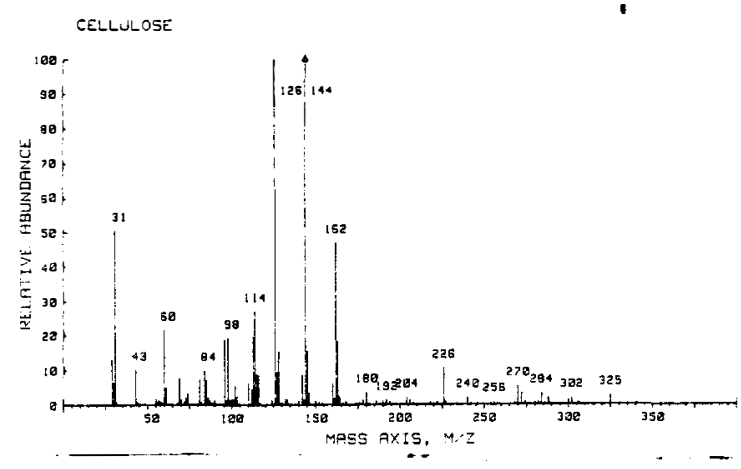

(b)

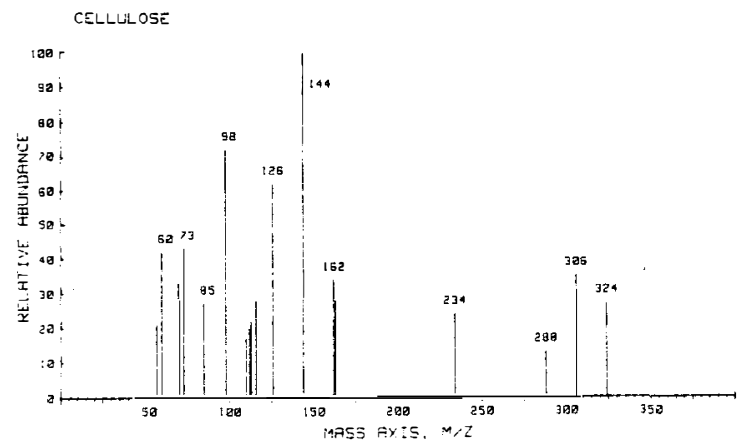

(a)

Figure 13a. A Comparison of Cellulose Pyrolysis Spectra. (a) Filter paper pyrolyzed in $900^{\circ} \mathrm{C}$ flame, low voltage electron impact (SERI). (b) Field ionization spectra of glycogen by Schulten and Görtz [14] (stated to be identical to cellulose spectrum). (c) Chemical ionization spectrum $-\mathrm{CH}_{4}$ (Hileman et al) [15] • (d) Laserinduced pyrolysis, electron impact (Lincoln) [17]. 


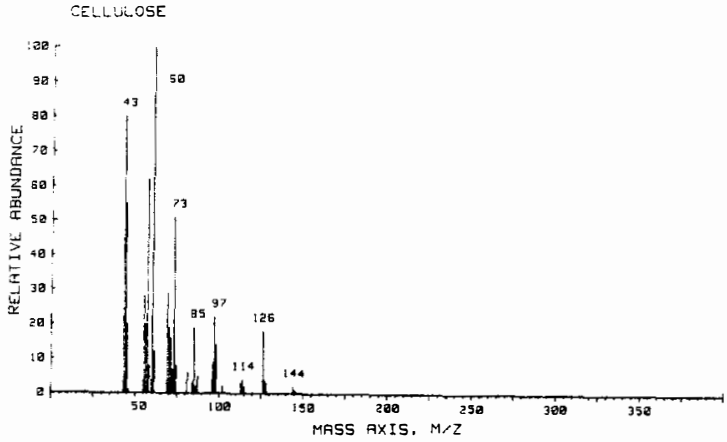

(c) 离

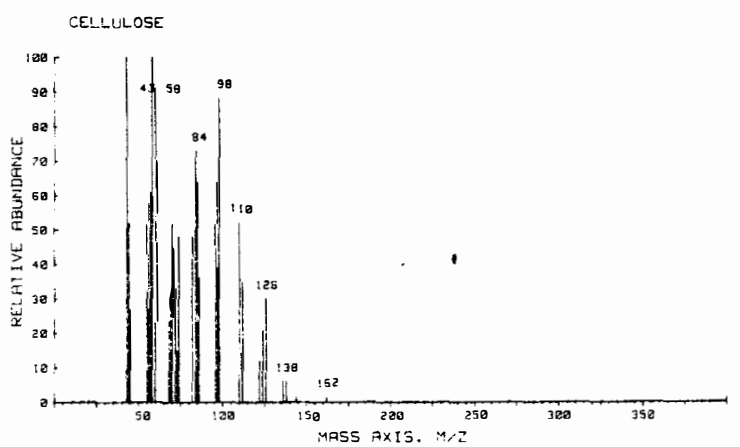

(b)

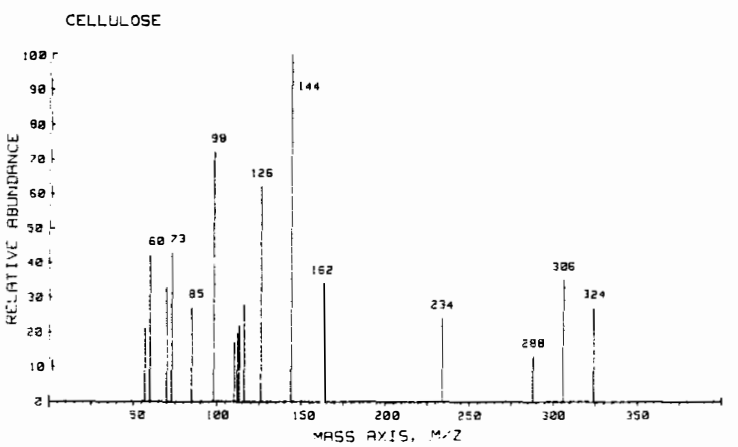

(a)

Figure 13b. A Comparison of Cellulose Pyrolysis Spectra. (a) Filter paper pyrolyzed in $900^{\circ} \mathrm{C}$ Flame. Low voltage electron impact (SERI). (b) Curie point pyrolysis. Low voltage electron impact (Meuzelaar) [13]. (c) Direct insertion probe spectra, high voltage electron impact (Franklin) [16]. 
conventional analytical spectra and the general conformity of our spectra with the field desorption spectra of Schulten(14). There are ways to explain the relative lack of heavy ions in the conventional pyrolysis spectra. These could include different tuning of the mass spectrometer; loss of less volatile components in the indirect inlets of most Curie-point and pyroprobe systems; mass separation of heavy ions in our system (first power of molecular welght enhancement of neutral species); pyrolysis under high-vacuum versus high-pressure pyrolysis; and temperature dependence of fragmentation patterns. (Our system and field-desorption probably achieve lonization with the least internal energy contribution to fragmentation with the exception of chemical ionization using gases such as $\mathrm{NH}_{3}{ }^{\circ}$ ) The details of the lonization behavior of primary pyrolysis products will be a subject of future study. For now we conclude that our system can yield a rich spectrum of heavy, primary products capable of quantification for mechanistic studies.

Figure 14 shows a more limited comparison of lignin spectra(18-20). One makes the same observations as for cellulose, with the caution that "lignin" is a much more variable material than cellulose. Our results agree quite satisfactorily with field ionization results of Schulten ${ }^{(20)}$ using the same sample of ethanolextracted, steam -exploded, aspen 1 ignin $(21)$.

\section{Cellulose Pyrolysis in Heated Grids}

The heated grid system shown in Figs. 4 and 5 has been tested initially with small strips of Whatman $\$$ k40 filter paper. Pieces $25 \times 8 \times 0.2 \mathrm{~mm}$ thick, weighing about $17 \mathrm{mg}$ are sandwiched between layers of 325 mesh stainless steel. The mesh is positioned about $5 \mathrm{~mm}$ from the sampling orifice. The chamber is filled with one atmosphere of gently flowing argon which is shut off just before heating the grid to minimize cross drafts. Figure 15 shows single Ion monitoring of mass $60^{+}$at three different final grid temperatures (about 580, 660, and $890^{\circ} \mathrm{C}$, respectively). The holding time at temperature is 20 seconds, but the primary pyrolysis is clearly over in a fraction of that time. (For comparison, a $60^{+}$emission profile 


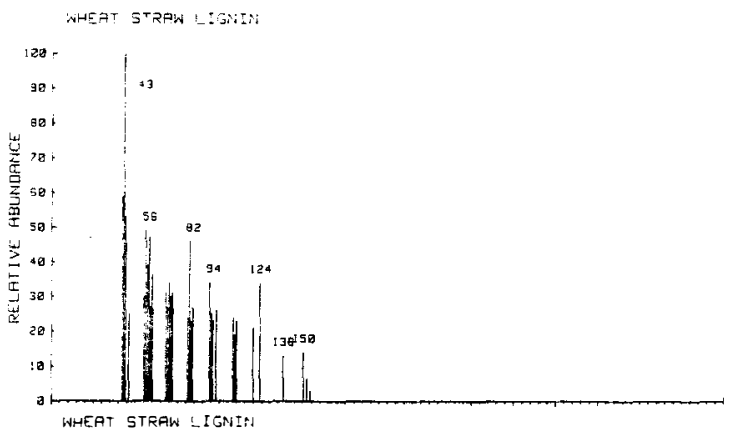

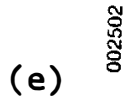

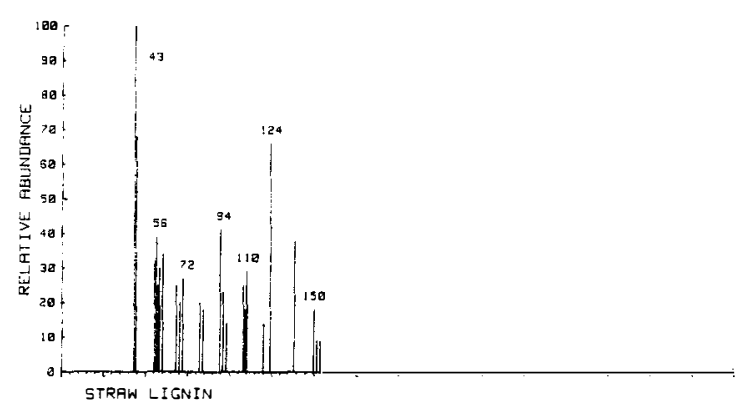

(d)

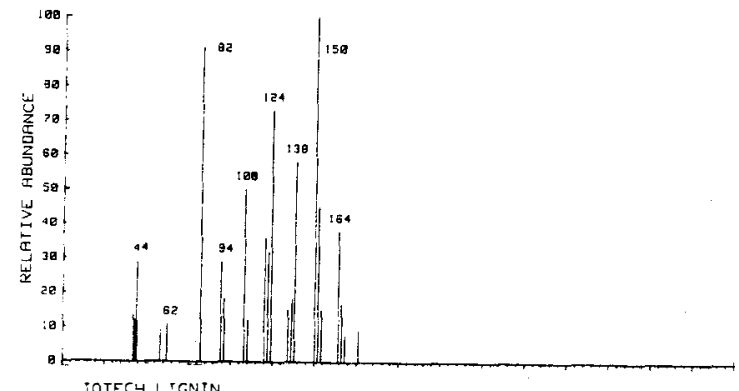

(c)

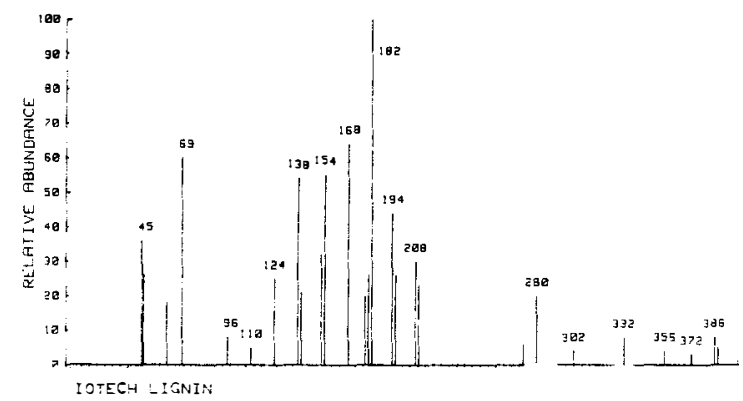

(b)

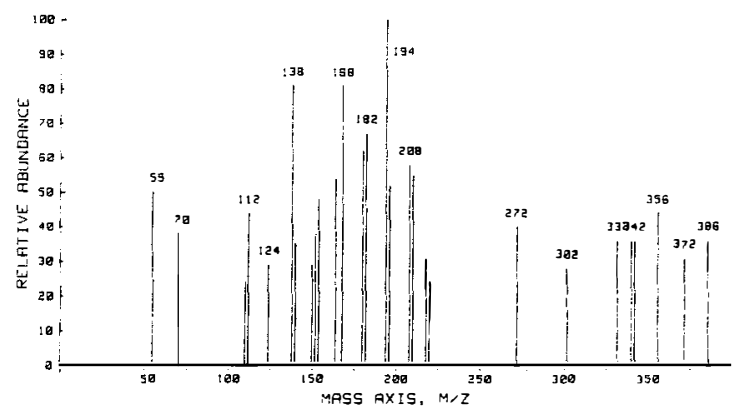

(a)

Figure 14. A Comparison of Some Lignin Pyrolysis Mass Spectra. (a) Steamexploded aspen lignin powder pyrolyzed in $900^{\circ} \mathrm{C}$ flame. Low-voltage electron impact (SERI). (b) Steam-exploded aspen lignin. Field ionization (Schulten)[20]. (c) Straw lignin. Curie point pyrolysis. Electron impact (Haider)[18]. (d) Wheat straw lignin. Curie point pyrolysis. Electron impact. (Meuzelaar et al.)[19]. 


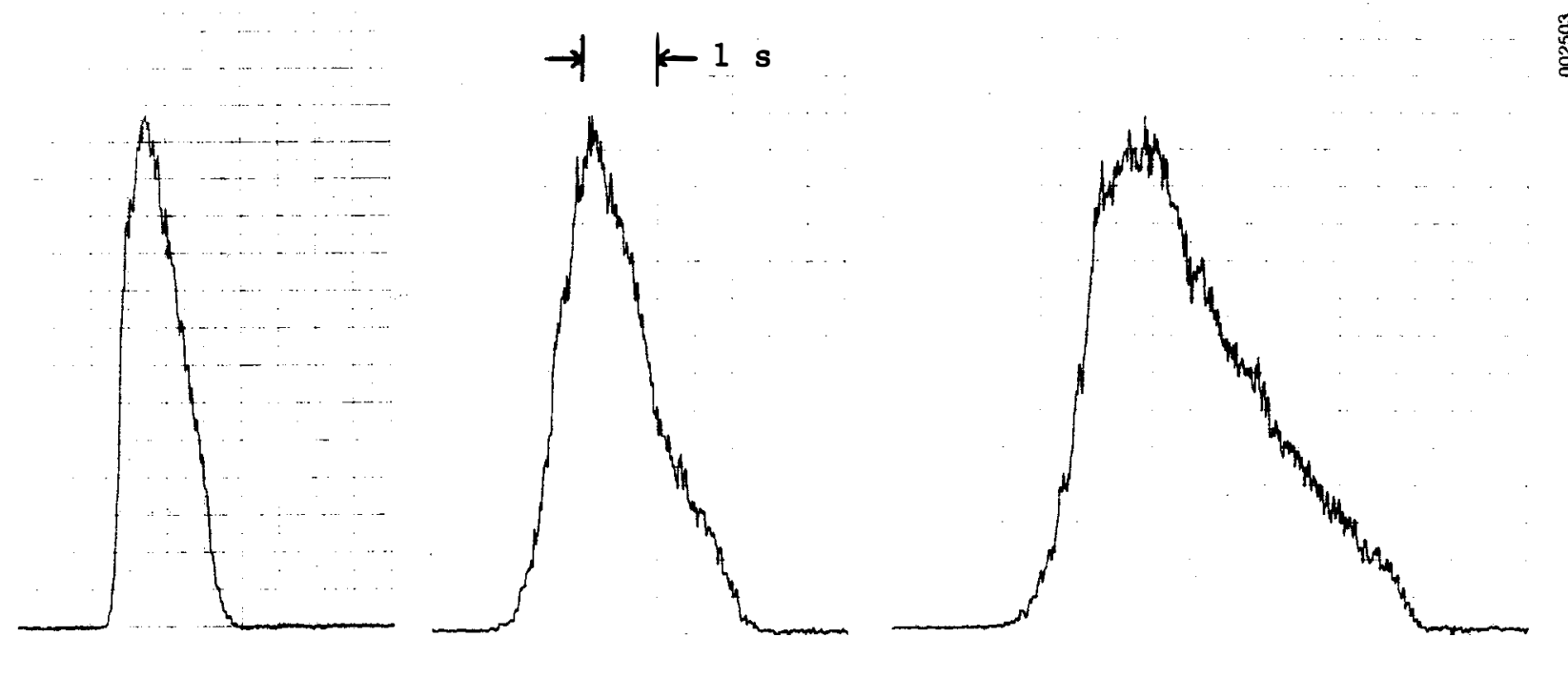

Figure 15. Pyrolysis Profiles for 60 from Cellulose (Filter Paper Strip), Captured in Heated-Grid. Sample size $25 \times 8 \mathrm{~cm} \times 0.2 \mathrm{~mm}$. One atmosphere cold argon. Orifice $5 \mathrm{~mm}$ from mesh top surface. Three heating levels. Full power achieved in $1 \mathrm{~s}$. Approximate peak temperatures are 890,660 , and $580^{\circ} \mathrm{C}$ and temperature holding time is $20 \mathrm{~s}$.

from a $17 \mathrm{mg}$ roll of filter paper in the $900^{\circ} \mathrm{C}$ flame gases persists for about 10 seconds.) It is apparent that the heated grid permits forced heating at considerably greater rates than from convective heating in the flame gases used to date. Figure 16 shows a complete spectrum of cellulose from the heated grid operated at the lowest temperature conditions shown in Fig. 15. The features of the spectra are quite similar to the spectra in hot flame gases, even though the primary products emerge into cold, surrounding argon. (Of course, some heating of the argon in the vicinity of the hot grid must occur.) It is gratifying to observe that immediate condensation of heavy materials does not seem to occur just above the grid prior to extractive sampling. The chamber does fill with "smoke," however, shortly after the grid is heated. Some of this material eventually finds its way into the pyrolysis gases sampled at times longer than the primary event. 


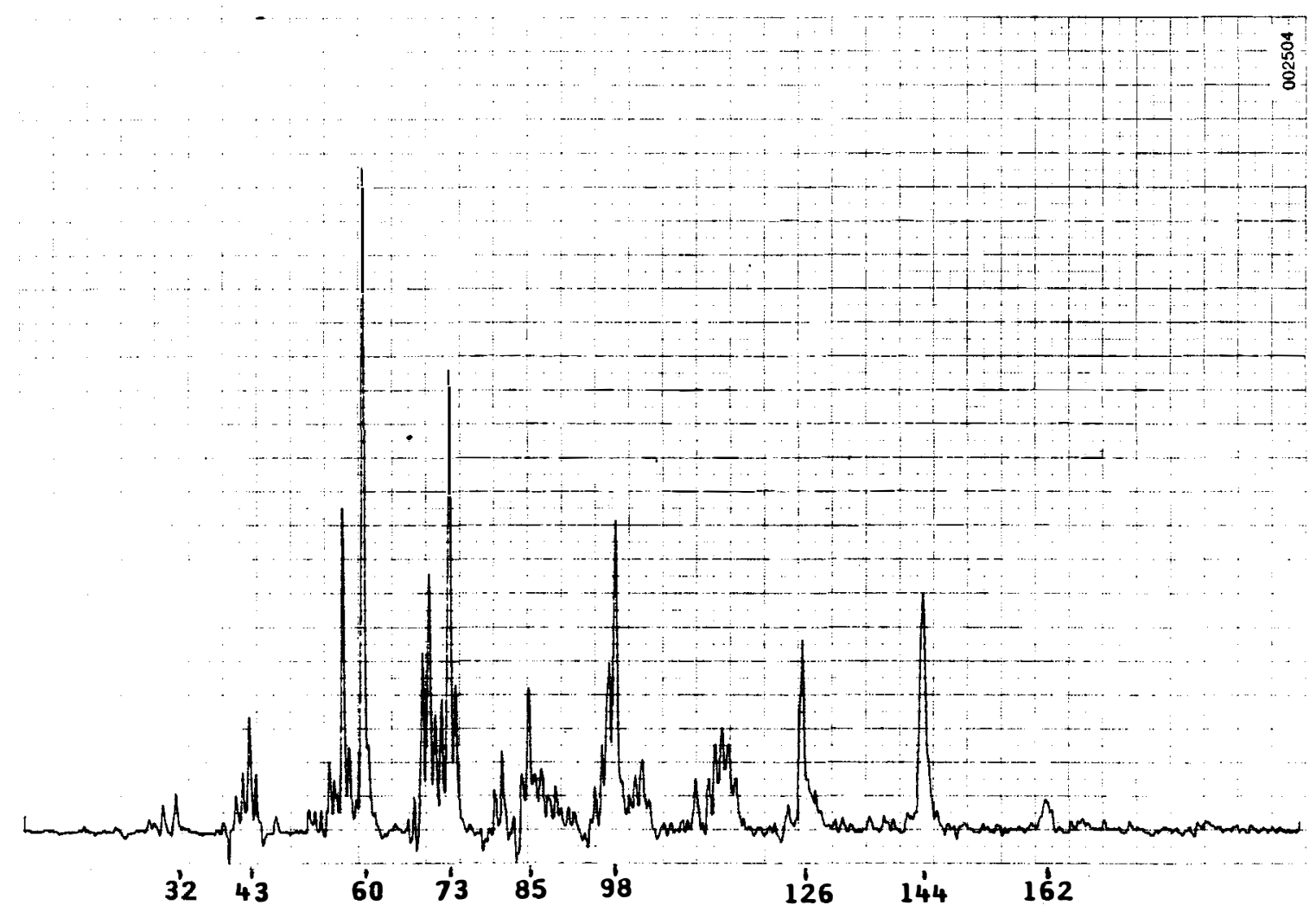

Figure 16. Spectrum of Cellulose at the Lowest Temperature Conditions Shown in Fig. 15. Sixteen 1 -s scans from 5$200 \mathrm{amu}$. $18 \mathrm{eV}$.

Time Dependence of Cellulose Primary Products

The recently acquired, digitally programmed, 16 -peak switching device for the Extranuclearm mass spectrometer has been tested with cellulose in hot flame gas pyrolysis. The system permits sequential switching between 16 preselected masses with dwell times as short as 5 ms. Figure 17 shows the time dependence of a number of masses during the pyrolysis of a $17 \mathrm{mg}$ roll of filter paper in $900^{\circ} \mathrm{C}$ steamargon. In this instance one of us [8] has directly interfaced the peak-switched output of the multichannel analyzer with an HP 9845 computer for data storage, manipulation, and plotting. Noteworthy in Fig. 17 is the perhaps complete conformity in the emission of products leading to the major heavy masses being monitored. Two explanations are: that all the lons are fonization fragments of one 



Figure 17. Time Dependence of Evolution of Species Responsible for Selected Ions then Filter Paper is Pyrolyzed in $900^{\circ} \mathrm{C}$ Steam/Argon 
parent ion (e.g., levoglucosan); or that the rate limiting step is the unzipping of the cellulose polymer (e.g., to levoglucosan) and subsequent decomposition (thermal fragmentation) is very fast. Future studies by Evans ${ }^{(8)}$ will address these questions in detail, extending the time-dependence studies to lower temperatures and faster heating rates.

Levoglucosan Pyrolysis Spectra

Early spectra of levoglucosan (11) showed great similarity to the cellulose spectra. We have begun an elucidation of this similarity by carrying out studies with a conventional direct insertion probe (DIP) a Hewlett-Packard analytical mass spectrometer system, using both electron impact and chemical ionization. Figures 18 and 19 compare spectra of levoglucosan under different lonization and instrumental conditions. Also included is a field ionization spectrum on the same sample, kindly supplied by Schulten ${ }^{(20)}$.

Comparison of the spectra in Fig. 18 shows that levoglucosan undergoes a good deal of fragmentation in the volatilization and lonization process. There are two possible explanations for this: (1) levoglucosan is thermally labile and is at least partially fragmented by the volitilization process, or (2) levoglucosan is being fragmented by the lonization process itself. The results in Fig. 18 could be interpreted along either line of reasoning. The electron impact DIP spectra shows increased fragmentation when the ion source temperature is raised from $64^{\circ} \mathrm{C}$ to $200^{\circ} \mathrm{C}$, indicating some possible thermal fragmentation. But both show much more fragmentation than chemical ionization using methane indicating that the lonization process is responsible for fragmentation. In contrast, the free-jet molecular-beam EI spectrum resembles the $\mathrm{CI}-\mathrm{CH}_{4}$ spectra more than the other EI spectra from the DIP. A plausible explanation for all these observations is that the free-jet adiabatic cooling presents molecules to the lon source with low levels of internal energy so that the electron beam lonizes a cool molecule giving a smaller degree of fragmentation. In the DIP, the molecules are thermally excited resulting in higher levels of frag- 


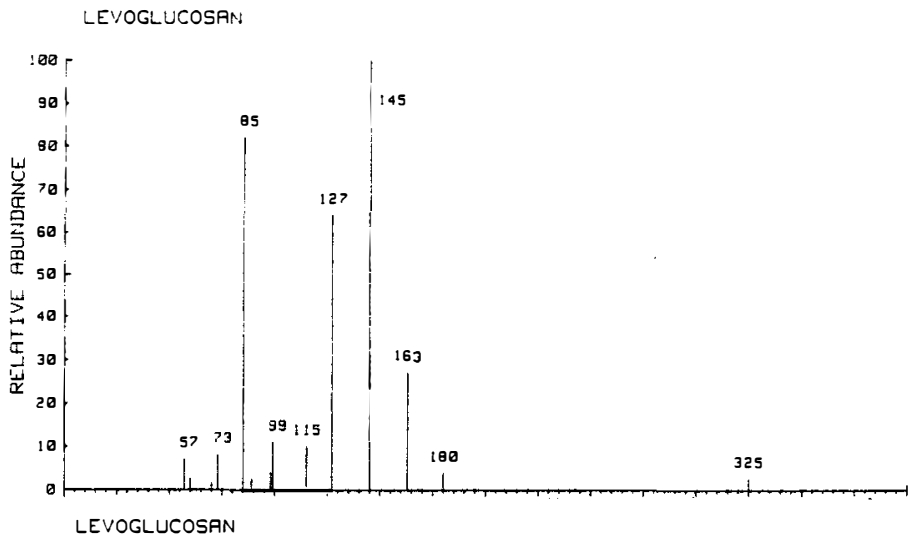

(d)

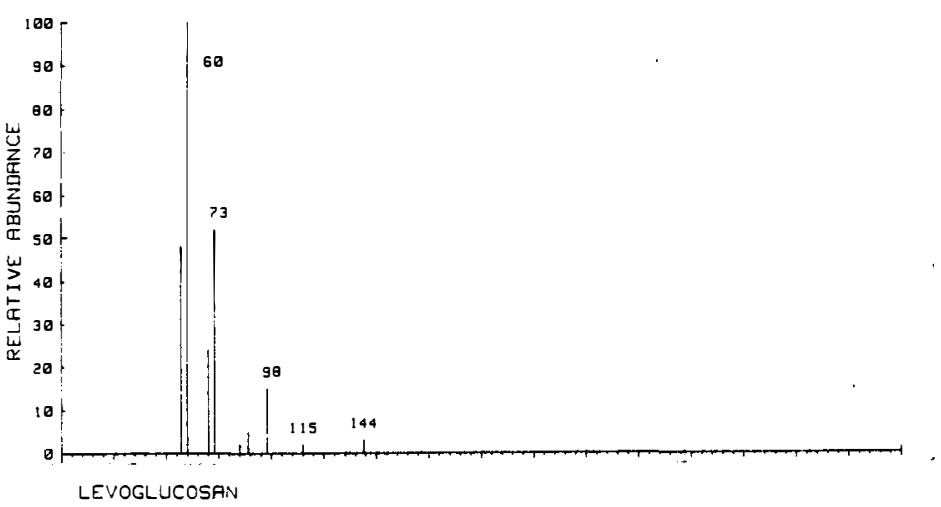

(c)

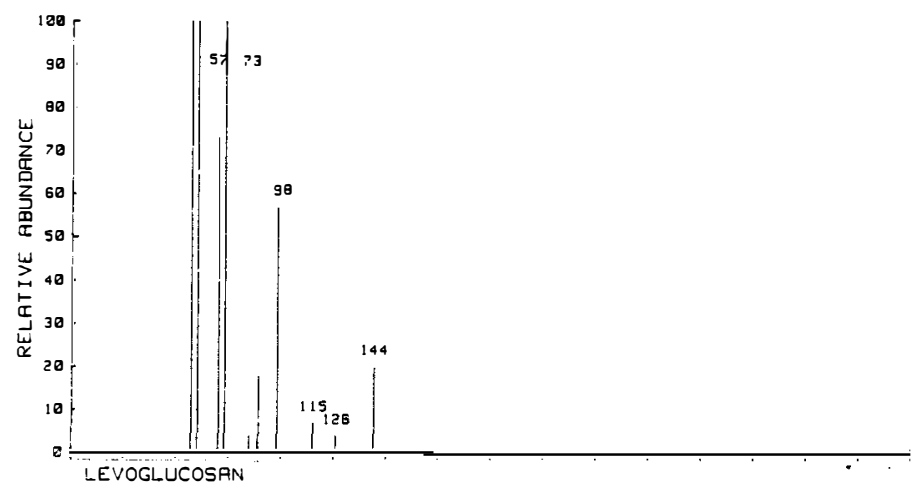

(b)

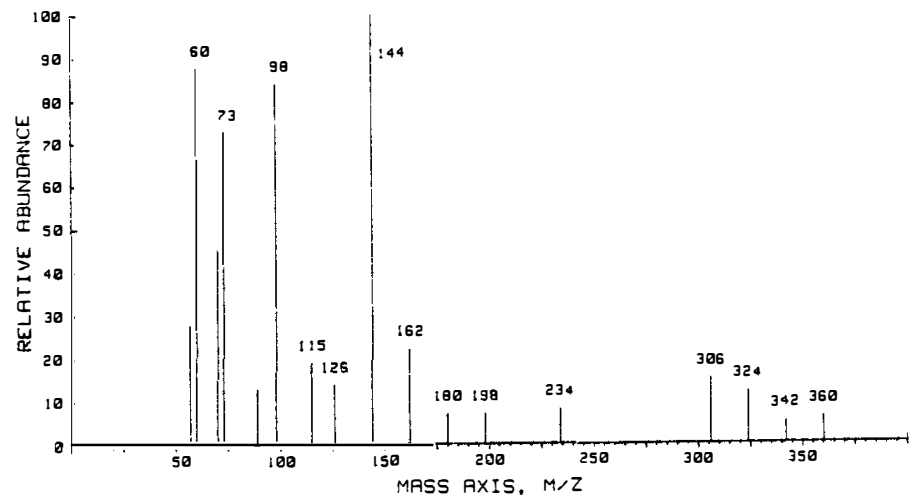

(a)

Figure 18. Comparison of Levoglucosan Mass Spectra. (a) Powder vaporized in $900^{\circ} \mathrm{C}$ flame. $16.5 \mathrm{eV}$ electron impact. (b) Direct insertion probe at $165^{\circ} \mathrm{C}$. Ion source at $64^{\circ} \mathrm{C}$. $16.5 \mathrm{eV}$. (c) Direct insertion probe at $165^{\circ} \mathrm{C}$. Ion source at $200^{\circ} \mathrm{C}$. $15.0 \mathrm{eV}$. (d) Direct insertion probe at $165^{\circ} \mathrm{C}$. Ionsource at $160^{\circ} \mathrm{C}$. Chemical Ionization by $\mathrm{CH}_{4}$. 


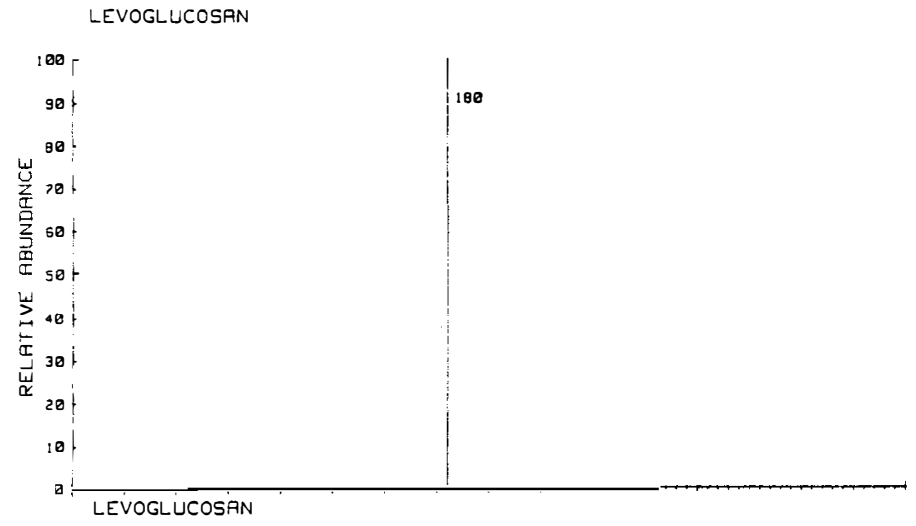

(d)

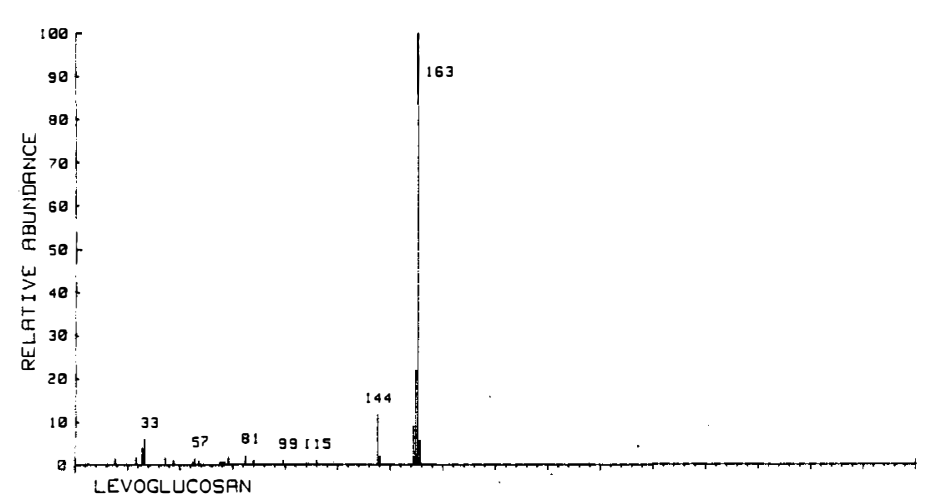

(c),

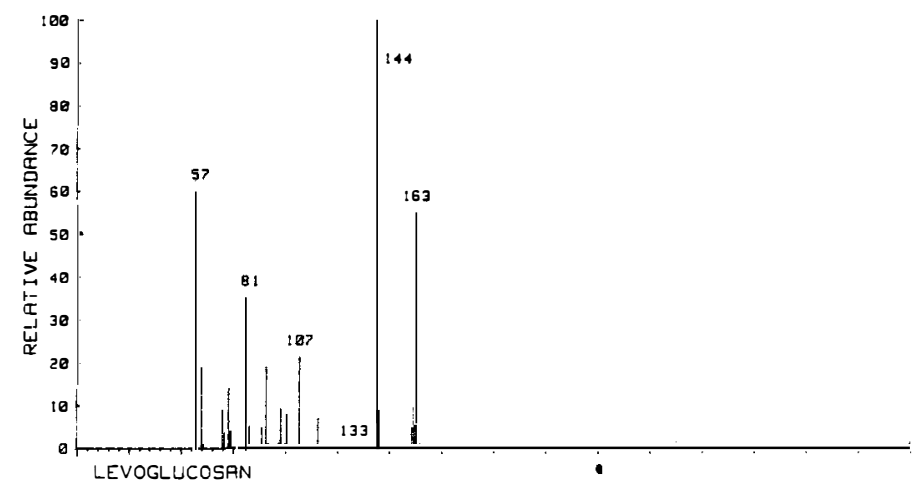

(b)

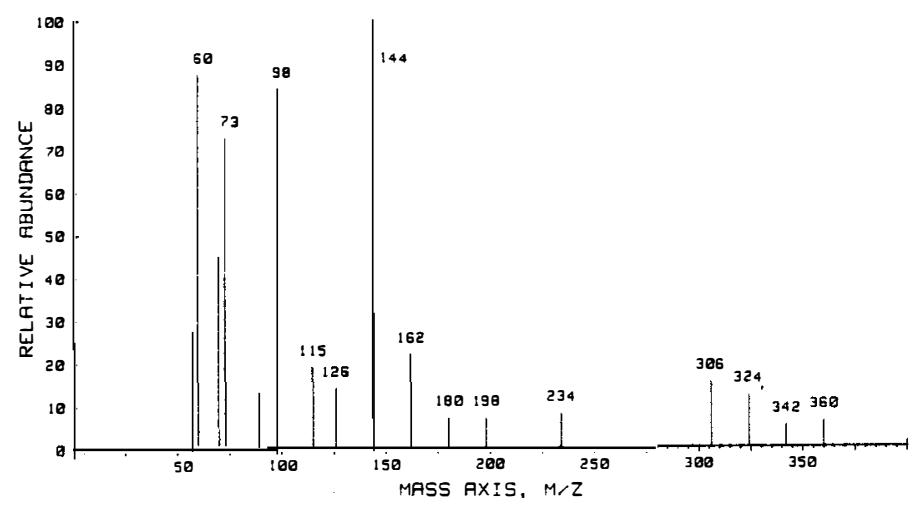

(a)

Figure 19. Comparison of Levoglucosan Mass Spectra. (a) Powder vaporized in $900^{\circ} \mathrm{C}$ flame. $16.5 \mathrm{eV}$ electron impact. (b) Field desorption. Source temperature $100^{\circ} \mathrm{C}$. (c) Field desorption. Source temperature $50^{\circ} \mathrm{C}$. (d) Direct insertion probe at $156^{\circ} \mathrm{C}$. Ion source at $160^{\circ} \mathrm{C}$. Chemical ionization by $\mathrm{NH}_{3}$. 
mentation of the hot molecule in the ionizing electron beam. Increasing the ion source temperature from $64^{\circ} \mathrm{C}$ to $200^{\circ} \mathrm{C}$ increases the amount of fragmentation due to the combination of higher thermal energy and the electron beam and not to pyrolysis that occurs during volatilization. The CI spectra, although with a $160^{\circ} \mathrm{C}$ ion source, has less fragmentation than EI because it is an inherently less energetic ionization process.

In Fig. 19, the spectra from CI of ammonia is shown to give only the molecular fon $\left(180^{+}=162^{+}+18^{+}\right)$. The addition of $\mathrm{NH}_{4}^{+}\left(18^{+}\right)$is the least energetic of the CI processes. The lack of fragmentation is strong evidence that levoglucosan fragmentation is due to the ionization process and not to pyrolysis, at least at these low temperatures.

The results from Schulten's field desorption work is not in agreement with the above explanation, since increased fragmentation occurs by increasing the ion source from $50^{\circ}$ to $100^{\circ} \mathrm{C}$. Field desorption is the least energetic ionization technique and such a large fragmentation pattern should not be observed by merely increasing the ion source temperature $50^{\circ} \mathrm{C}$. The observed results may be due to catalytic effects of the emitter, since in thermal desorption the sample must be coated on the emitter and some catalytic activity may be possible. Future work is planned to resolve these'questions.

These results indicate that by using the free-jet molecular-beam sampling system, levoglucosan can be detected quantitatively since a parent ion with $20 \%$ relative intensity is produced. However, other potential pyrolysis products such as levoglucosenone (126), 3-deoxy1,6 -anhydroglucopyranose (144), and species at masses $98,85,73$, and 60 will be masked by levoglucosan ionization fragments and therefore will be more difficult to quantitate. A more quantitative comparison of cellulose and levoglucosan spectra, for the low mass range, is shown in the next section. 


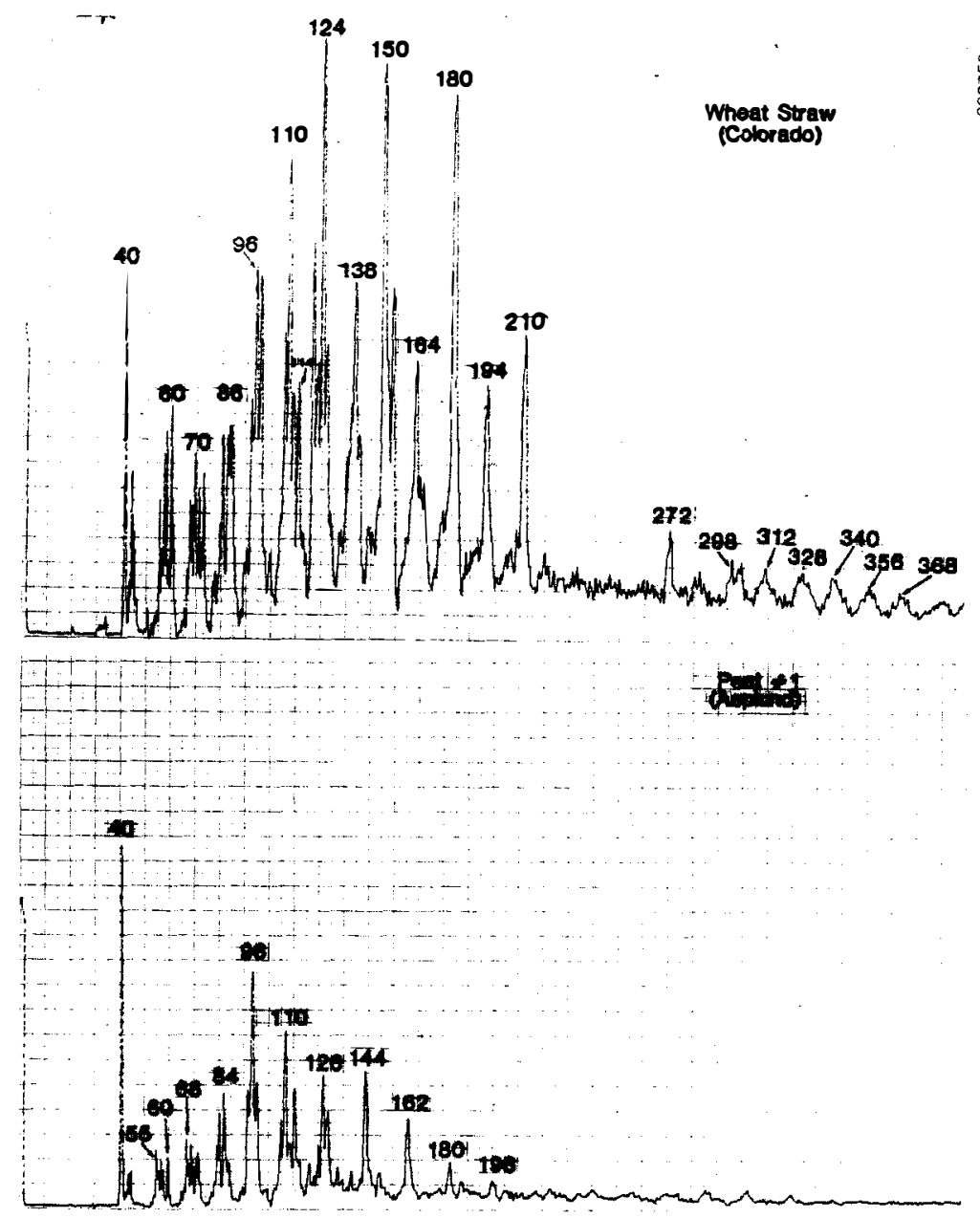

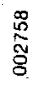

\section{Antedento}

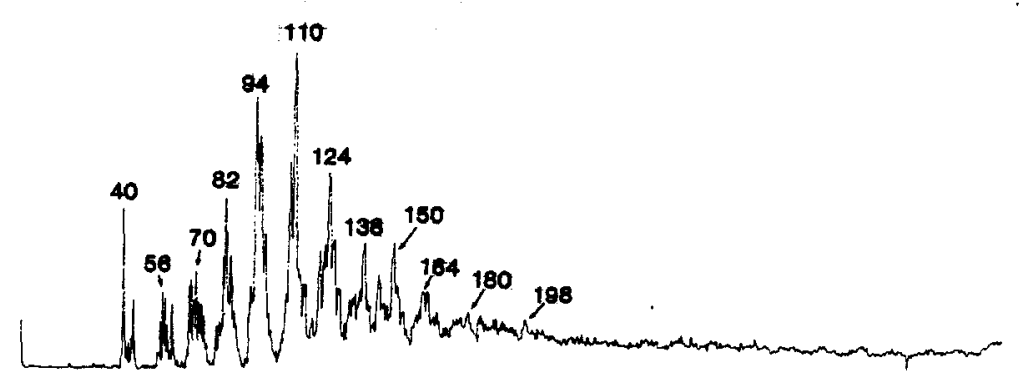

Figure 20. Mass Spectra (Low Voltage of theat Straw and Peat Samples in $900^{\circ} \mathrm{C}$ Argon/Steam. High masses emphasized. Peats $\|_{1}$ and $\$ 2$ appear to be h1gh moor and low moor, respect1vely. 
Spectra of Miscellaneous Materials--Fingerprinting

Recent reports $(1,2,3,11)$ have included qualitative spectra for a range of carbonaceous materials. Shown here are several examples to illustrate the analytical utility of the high-mass fingerprinting type of experiment. In Fig. 20 is shown the spectrum of two peat samples, kindly supplied by Asplund ${ }^{(22)}$ and the spectrum of a Colorado wheat straw.

In Fig. 21 is shown a spectrum of polyethylene pyrolyzed in hot flame gases. Noteworthy are the extremely high molecular weight fragments preserved without derivatization. Characteristic signatures are obtained for other plastics as well (3). Such fingerprinting may be useful in the qualitative characterization of wood-derived oils. Spectra (high mass tuning conditions) are shown for three oils, derived from different gasifiers, in Fig. 22. These

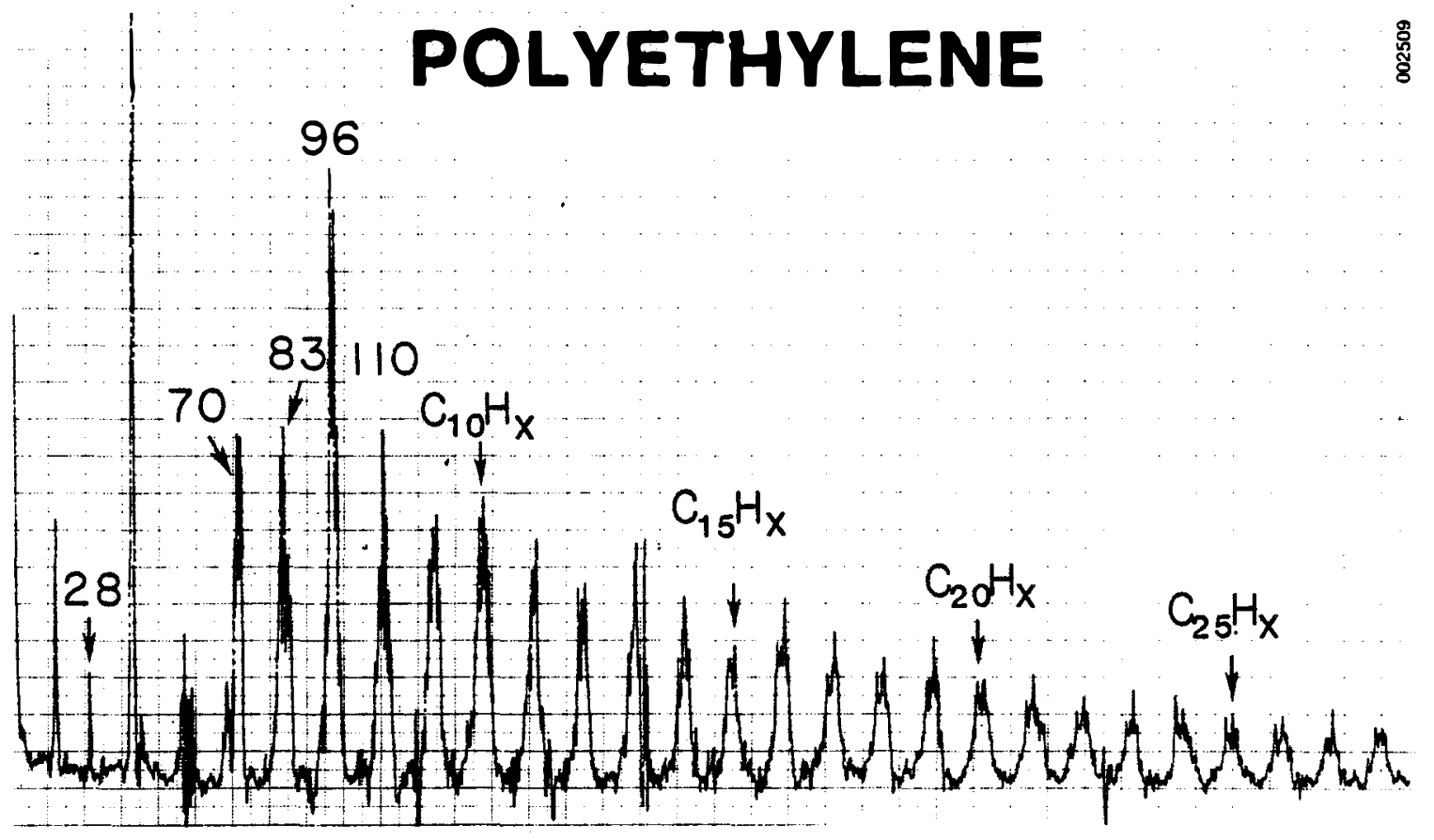

Figure 21. Spectra of Polyethylene Pyrolyzed in $900^{\circ} \mathrm{C}$ Steam/Argon. $17 \mathrm{eV}$ electron energy. 

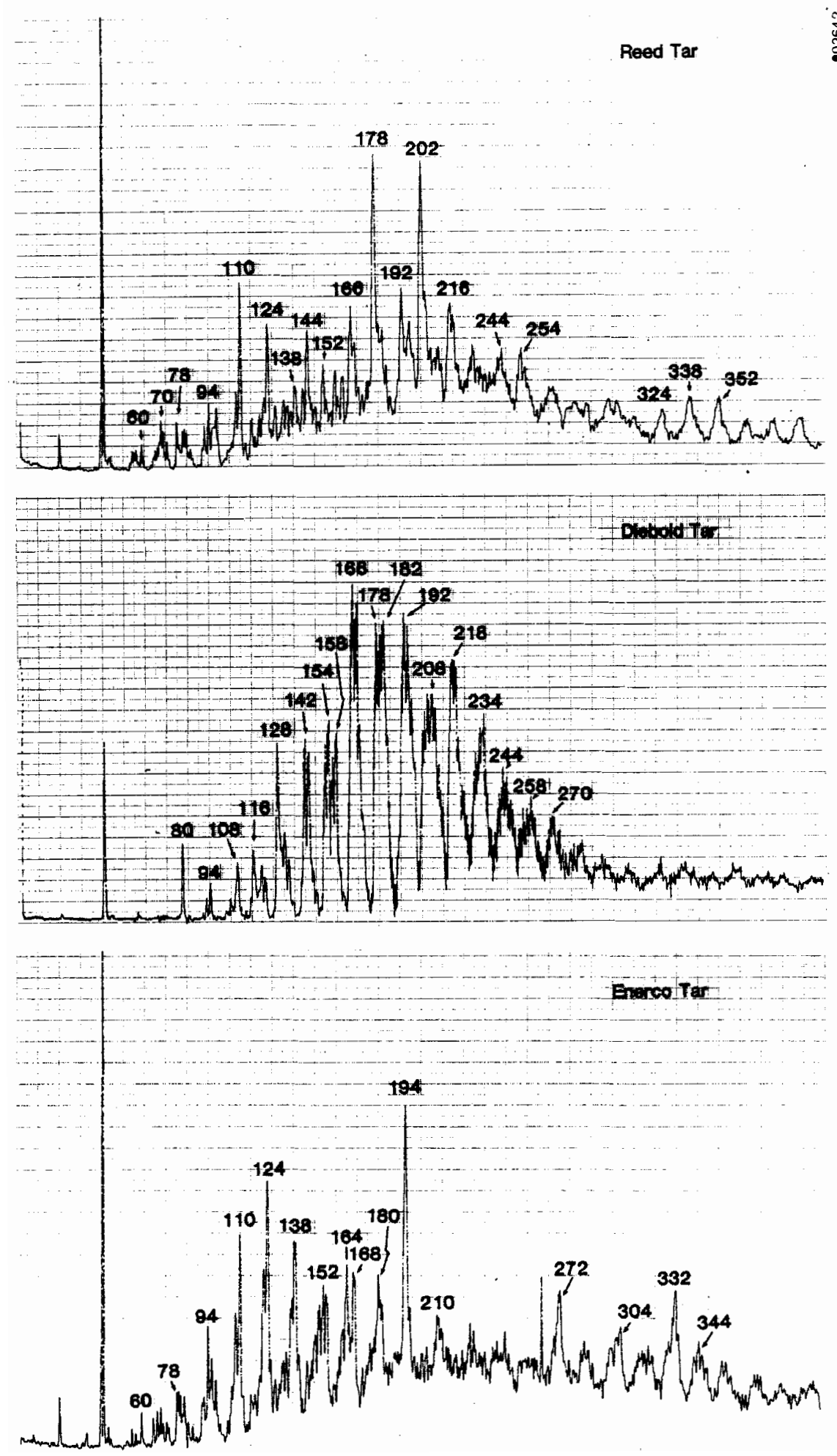

Figure 22. High Mass Spectra of Three Pyrolyis Oils (exact origin not well defined--shown for illustration of "fingerprinting" possibilities only. 
spectra are meant to be suggestive only. We are in the process of improving the tuning conditions of the mass spectrometer, in the high mass range, in order to make a more careful and controlled comparison of oils (and the feedstocks from which they were derived) that are being provided to us by a number of researchers in North America.

We have now established a standard, reproducible set of ionization and mass spectrometer tuning conditions for the mass range 12 to 200 amu. Under these conditions we are using mixtures of gases and liquids to determine quantitative mass spectral response of pure compounds suspected of being in the primary and secondary pyrolysis slates from woods. In Figs. 23 to 28 are shown a representative set of such spectra, with resolution such that mass assignments are unambiguous.

SECONDARY CRACKING --PRELIMINARY RESULTS

The sheathed flame gases apparatus shown in Fig. 3 has been tested with cellulose, lignin, and wood. The system works well mechanically and appears suitable for quantitative work. Both single and triple specimens give good spectra and signal-to-noise can undoubtedly be improved. A hot-wire spark igniter has been added just above the burner surface and small leaks sealed to insure no air enters the colum of gases (this has been verified by mass spectra obtained with no specimen in place).

Figures 29-31 show the trends in secondary cracking as the primary products travel from $5 \mathrm{~mm}$ to $160 \mathrm{~mm}$ in the approximately $900^{\circ} \mathrm{C}$ gases before being sampled and rapidly quenched. In comparing the changes in the spectra with distance, most significant are the changes in type and relative proportions of ions within one spectrum. A rather large diffusion correction will probably have to be applied to plot quantitative changes in any one ion with distance.

Figure 29 shows the behavior of cellulose at an ionizing electron energy of about $20 \mathrm{eV}$. From 5 to $10 \mathrm{~mm}$ above the surface, the spectrum is only slightly altered and the familiar cellulose spectrum is present. Between 10 and $20 \mathrm{~mm}$, major cracking has occurred, mass $78^{+}$(benzene) is becoming prominent and some intermediate olefins are 

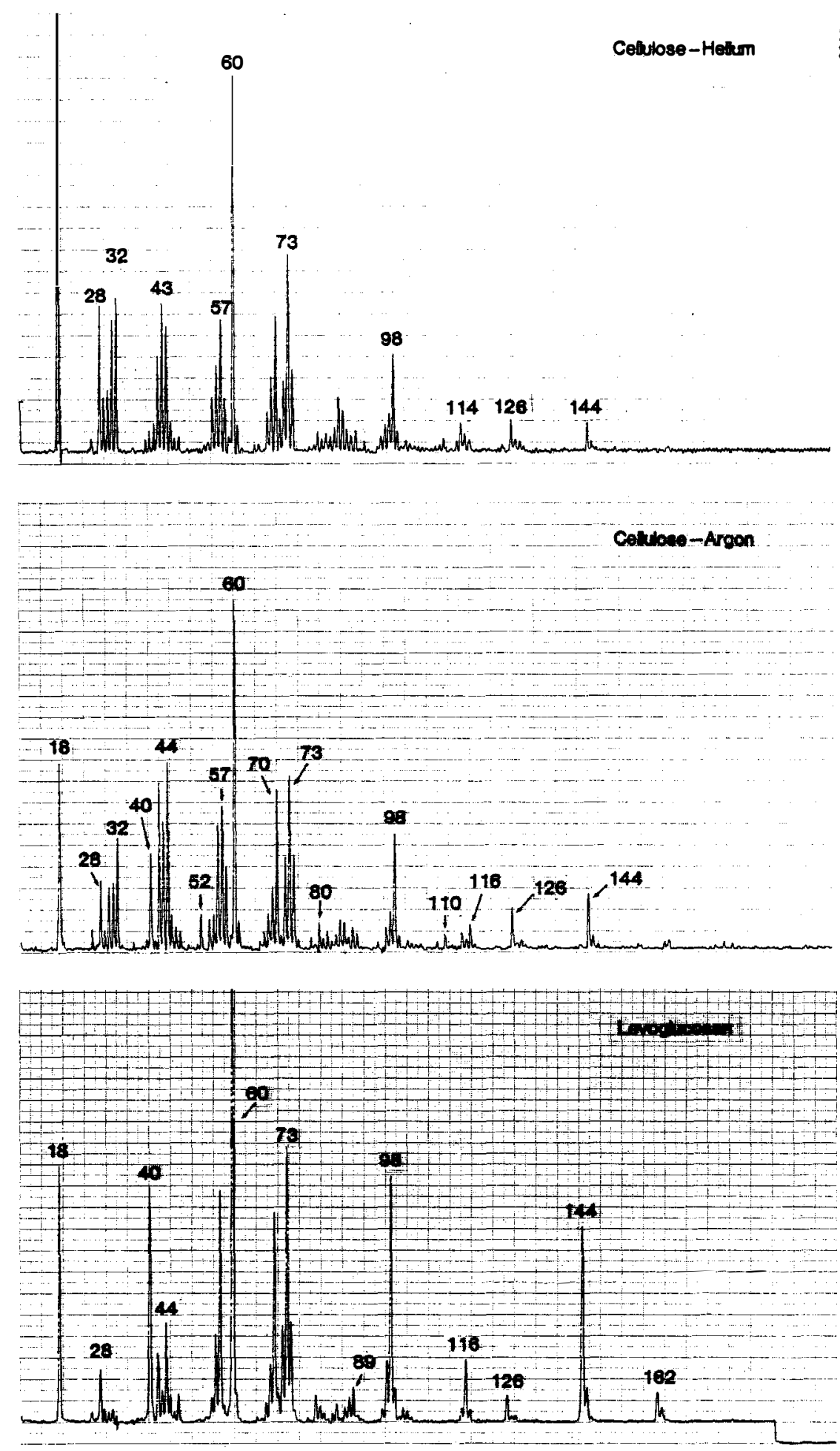

\section{Figure 23. Mass Spectra of Several Materials Under the Standard Conditions Chosen for Quantitative Calibration at Low Masses.}




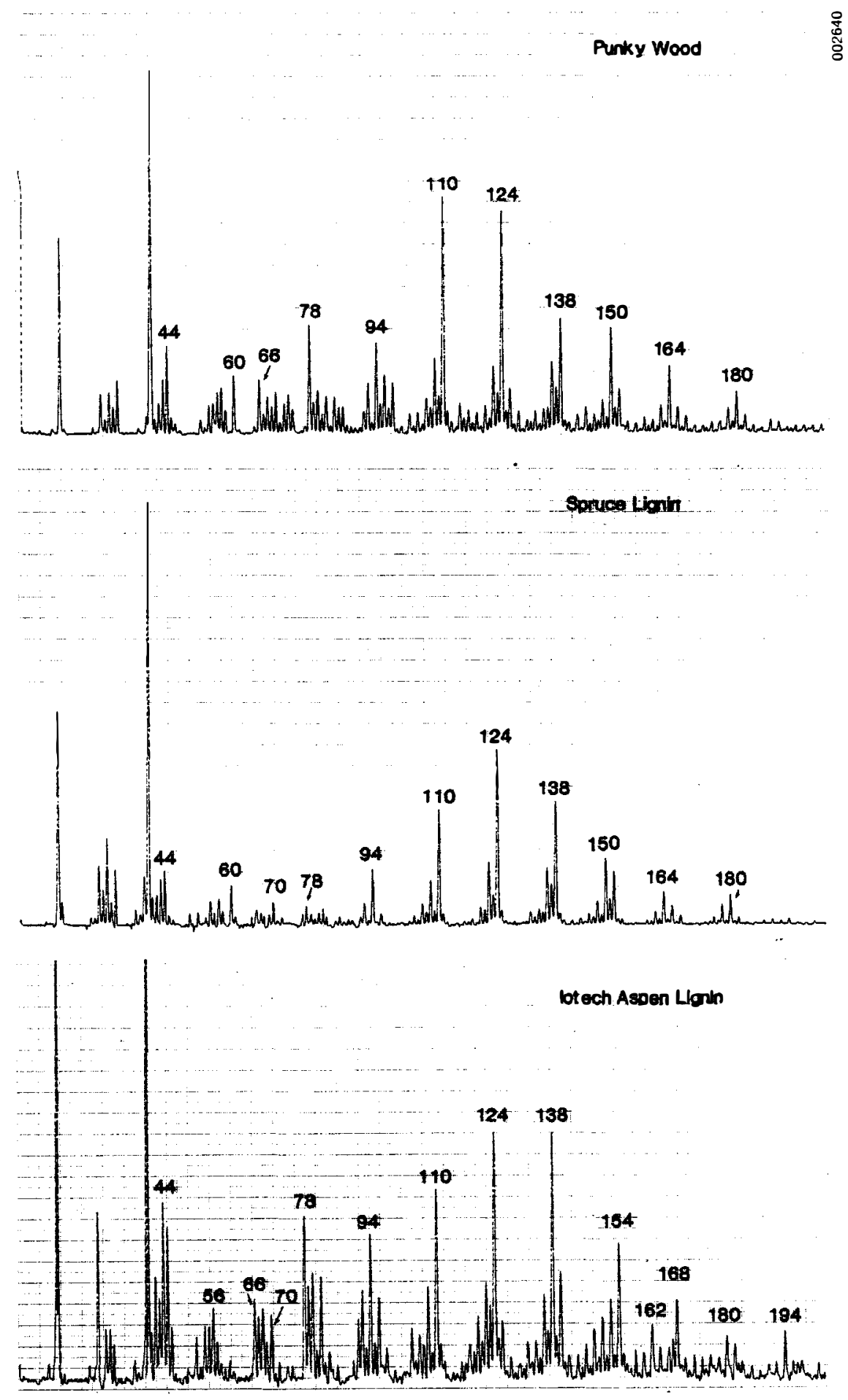

Figure 24. Mass Spectra of Several Materials Under the Standard Conditions Chosen for Quantitative Calibration at Low Masses. The punky wood derives from pine and is mainly lignin. Note the virtual absence of dimethoxy phenol peaks at 154 and 168 in the soft woods. 

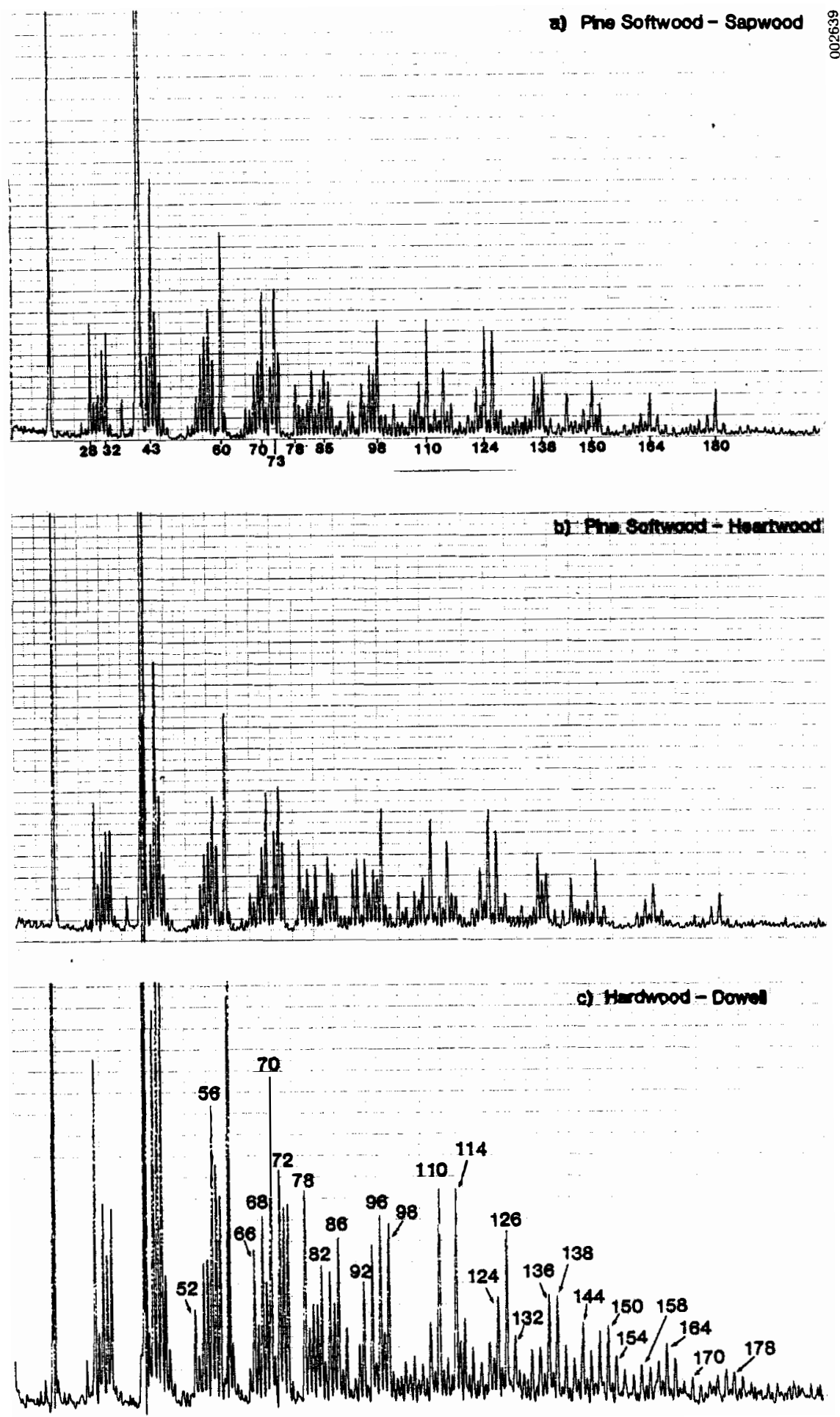

Figure 25. Mass Spectra of Several Materials Onder the Standard Conditions Chosen for Quantitative Calibration at Low Masses. Note the lack of significant difference in the spectrum of kiln-dried pine heartwood and sapwood. 

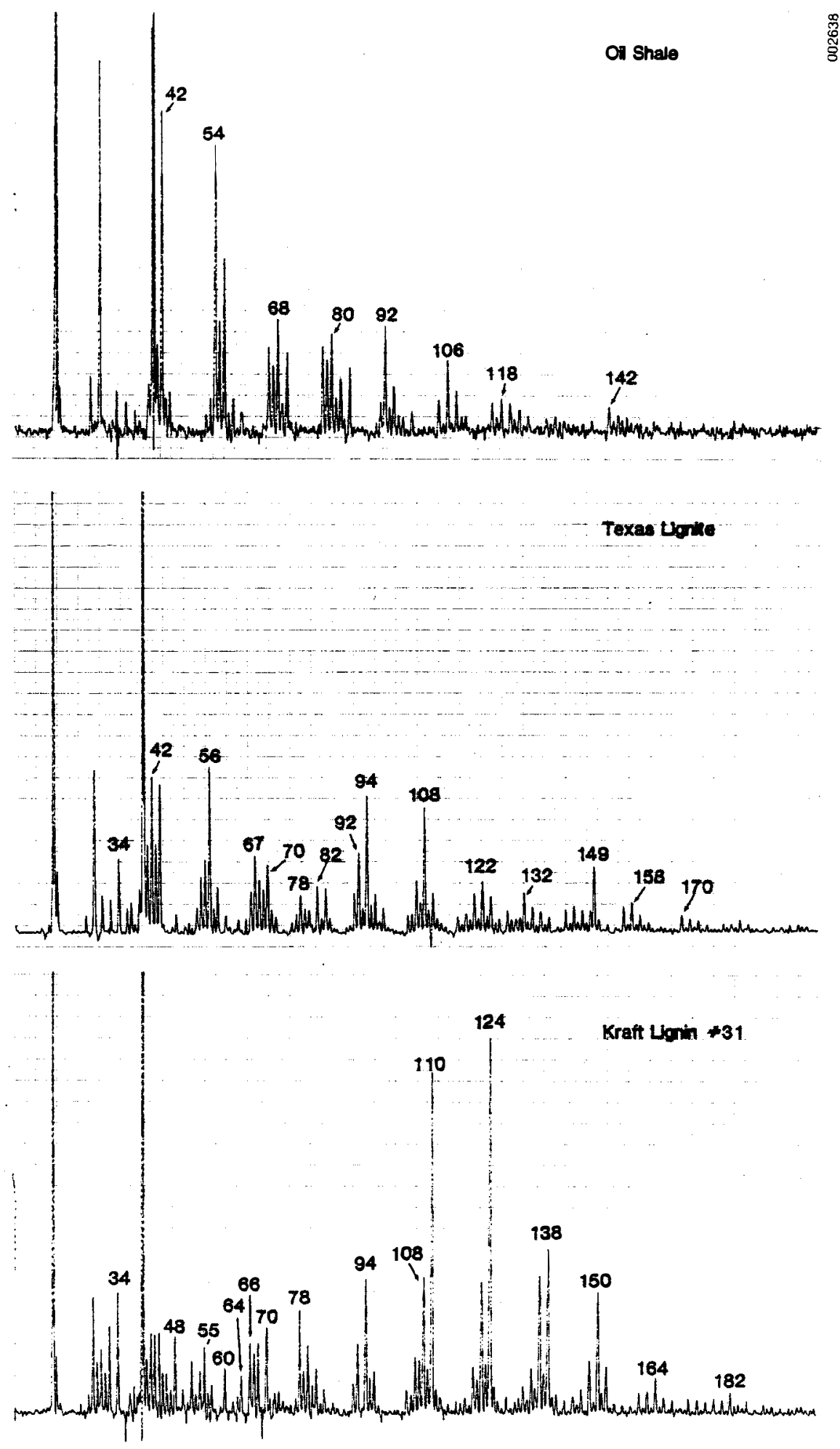

\section{Figure 26. Mass Spectra of Several Materials Under the Standard Conditions Chosen for Quantitative Calibration at Low Masses.}



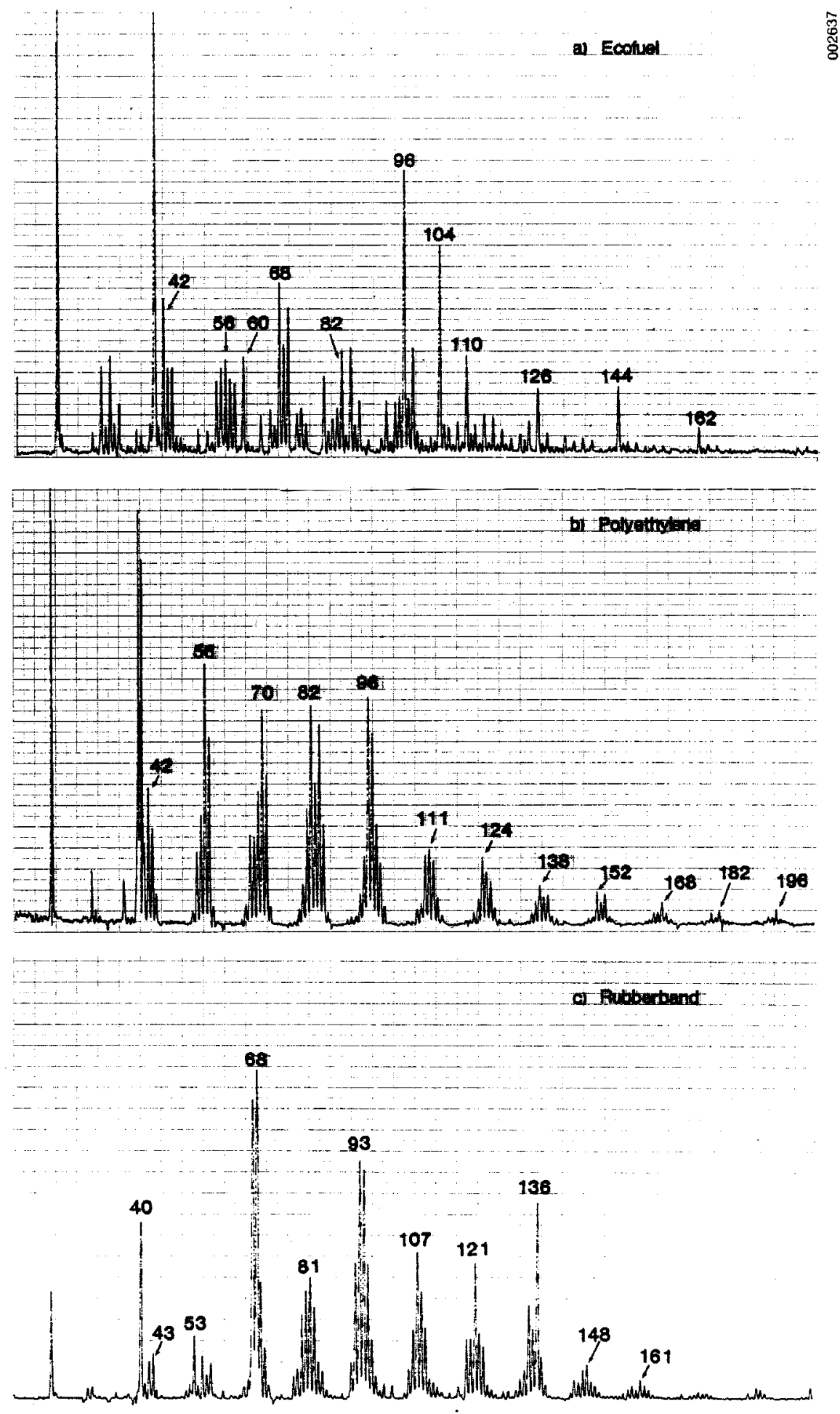

Figure 27. Mass Spectra of Several Materials Under the Standard Conditions Chosen for Quantitative Calibration at Low Masses. Note the greater richness of the Ecofuel (solid waste derivative) sample vis-a-vis cellulose. 

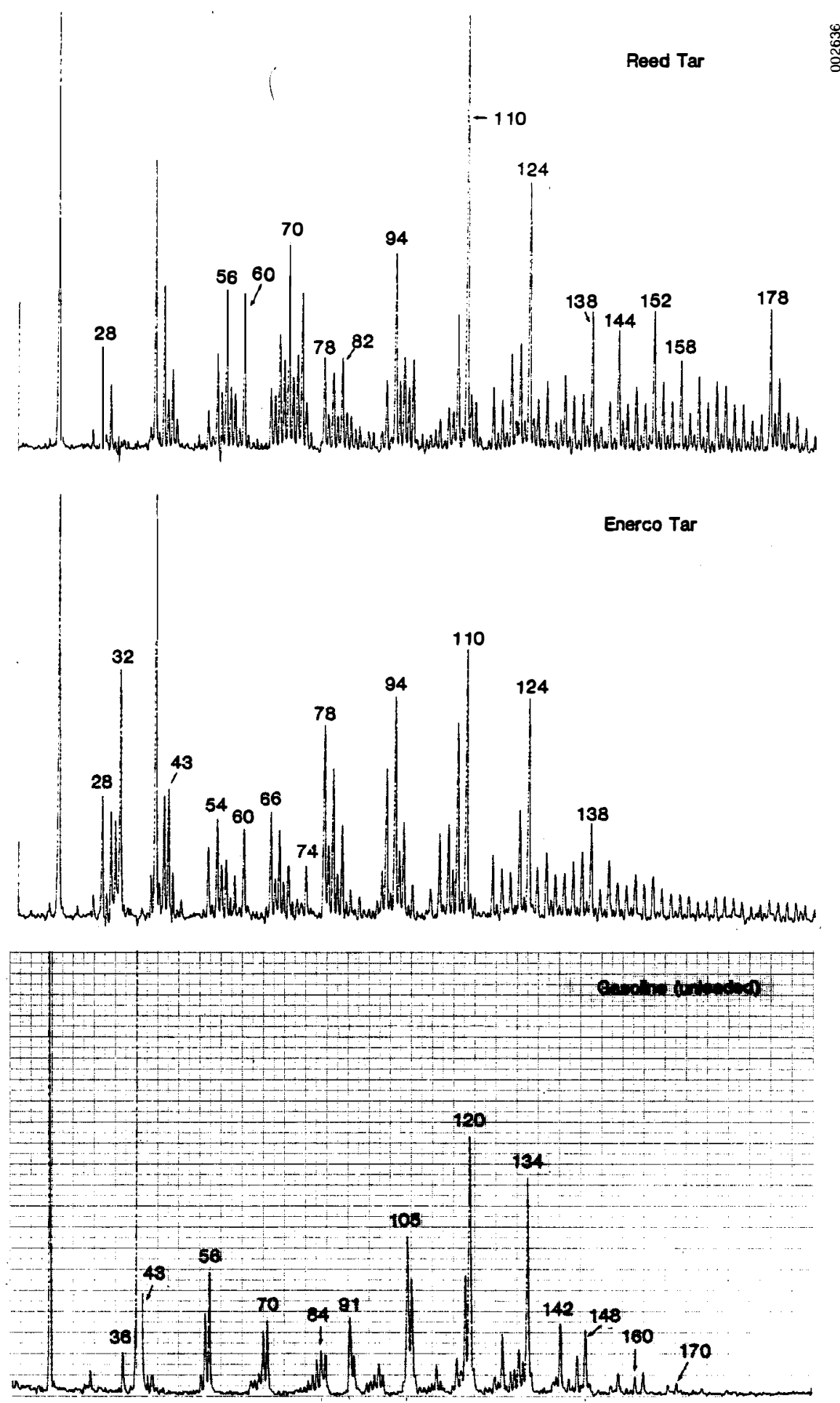

F1gure 28. Mass Spectra of Several Materials Under the Standard Conditions Chosen for Quantitative Calibration at Low Masses. The gasoline spectrum may be deficient in lighter fractions due to premature flash-off in the presently used flame gas environment. 


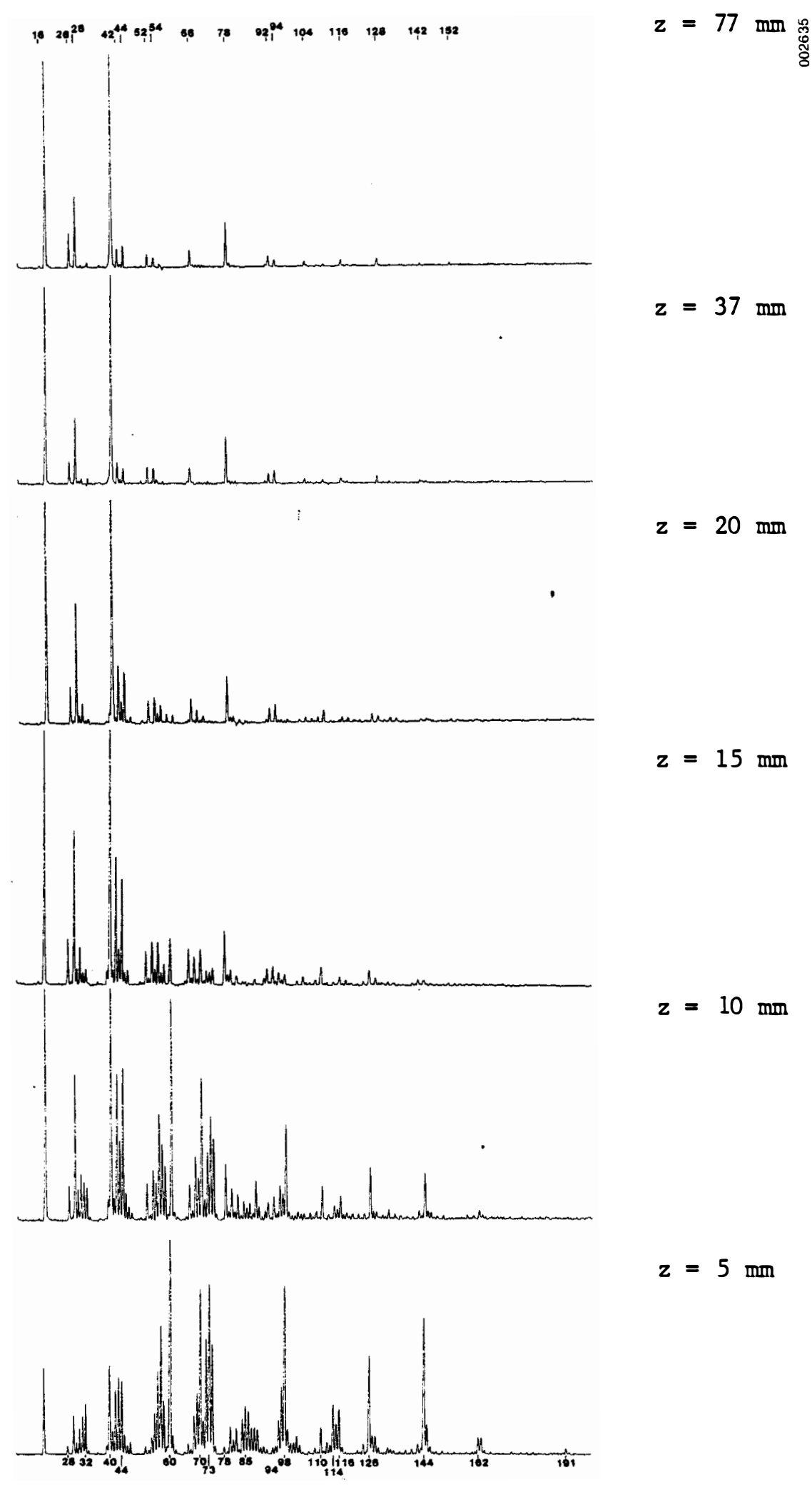

Figure 29. Secondary Cracking of Primary Pyrolysis Products from
Cellulose. 
probably present. At $40 \mathrm{~mm}$ only a few peaks predominate: $28^{+}$ (ethylene, $\mathrm{CO}), 44^{+}\left(\mathrm{CO}_{2}\right.$, propane), $66^{+}$(probably cyclopentadiene from thermal decomposition of toluene or phenol since these pure compounds give little $66^{+}$at low lonizing electron energies), $92^{+}$ (toluene) and $128^{+}$[possibly naphthalene, which has been detected in the fast pyrolysis of wood ${ }^{(23)}$ ].

Figure 30 shows similar data for ethanol-extracted, steamexploded lignin. The primary products seem more refractory and complex changes are shifting the product slate toward lower molecular weight species. Benzene is a major product ion. The prominent $66^{+}$ peak is higher than can be attributed to the toluene $\left(92^{+}\right)$or phenol $\left(94^{+}\right)$. (The reader is cautioned not to correlate ion intensities automatically with relative abundances. At these low ionizing electron energies, species with low appearance potentials can easily be over represented in the positive ion mass spectrum.)

Finally, in Fig. 31, the cracking of pine wood is shown. Some new peaks appear to be present, perhaps due to the hemicellulose or extractives components, but the general behavior is consistent with the cellulose and lignin behavior. It appears that $900^{\circ} \mathrm{C}$ and 10-100 ms time scales are matched to achieve major cracking of primary products from wood and its major components.

Because of its relevance in sorting out complex spectra like those just shown, some data for the cracking of methane and propylene in the $900^{\circ} \mathrm{C}$ flame gases are shown in Figs. 32 and 33 . Making a first order correction for diffusion, and recognizing that the sensitivity for detection of $\mathrm{CH}_{4}$ is only about $1 / 20$ th that for ethylene under the conditions of the experiment (low ionizing electron energy), the methane is seen to undergo only very slight decomposition in the approximately $50 \mathrm{~ms}$ at $900^{\circ} \mathrm{C}$. The products seen are most likely acetylene, ethylene, ethane, and $\mathrm{CO}_{2}$, but only in fractional percentages. The propylene shows considerably more cracking under the same conditions (curves for $n$-butane, ethane, and methanol were shown previously $(24,25)$ with the likely production of ethylene, acetylene, propyne $\left(39^{+}\right)$and methane). 


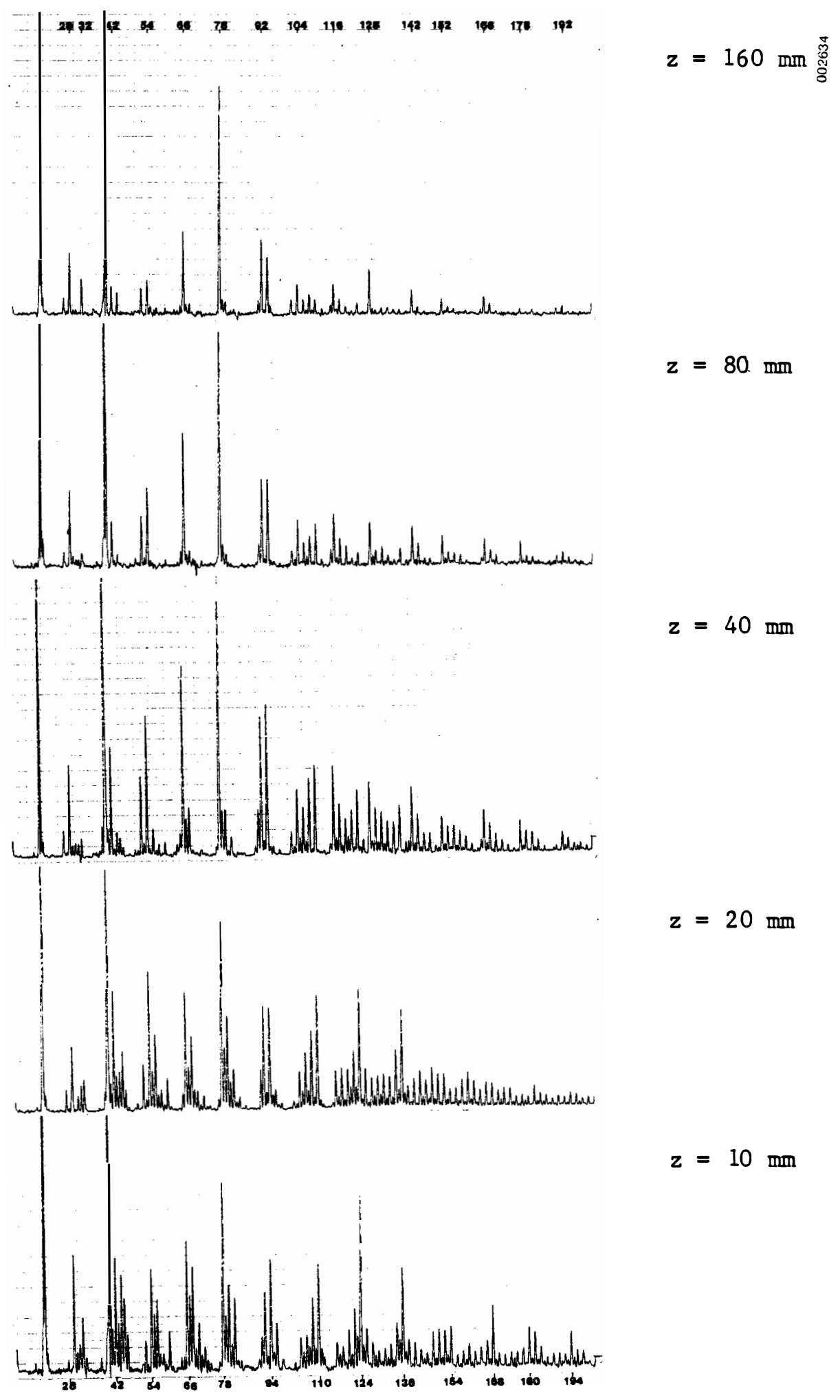

Figure 30. Secondary Cracking of Primary Pyrolysis Products from Steam-Exploded Aspen Lignin. 


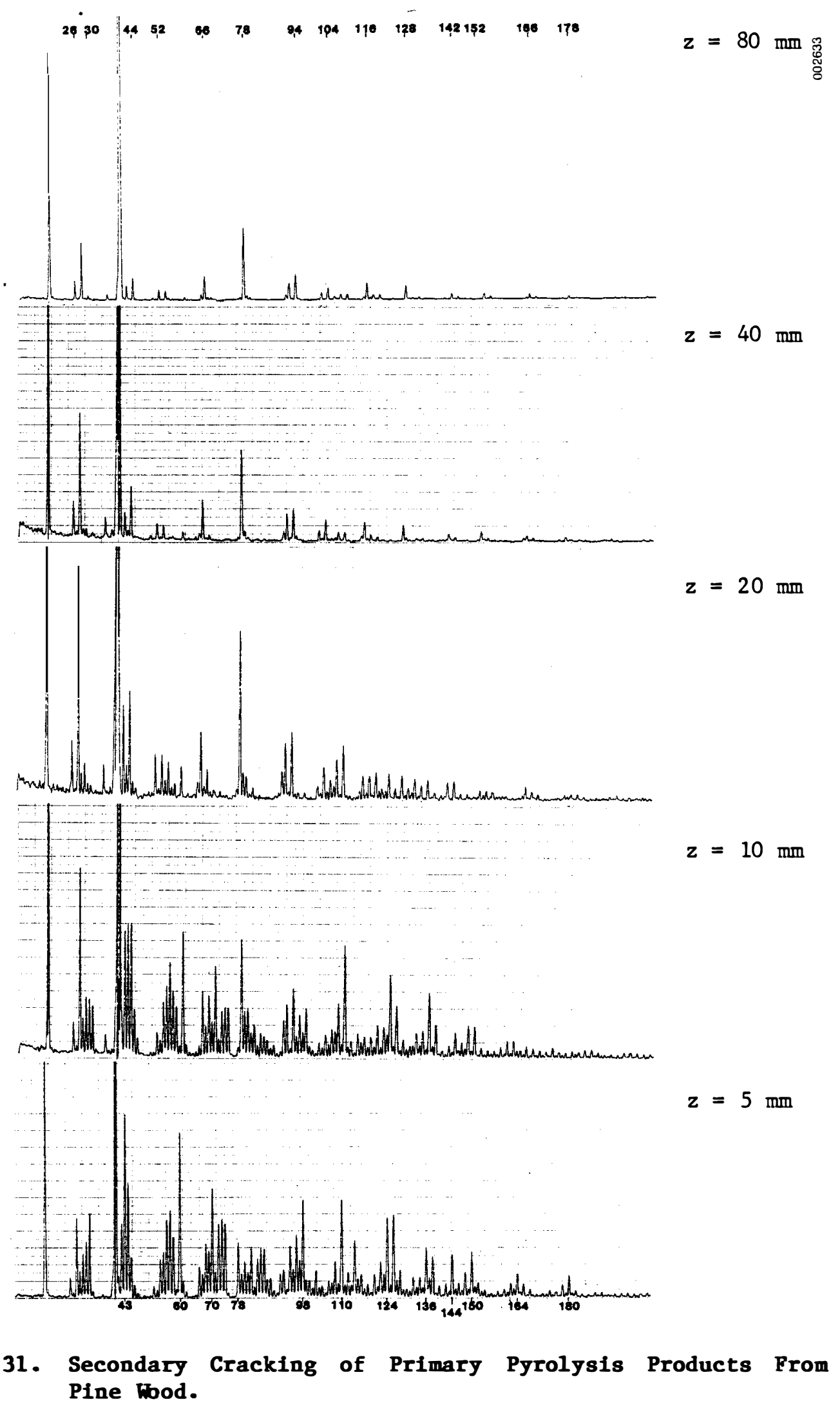

Figure 31. Secondary Cracking of Primary Pyrolysis Products From Pine hood. 


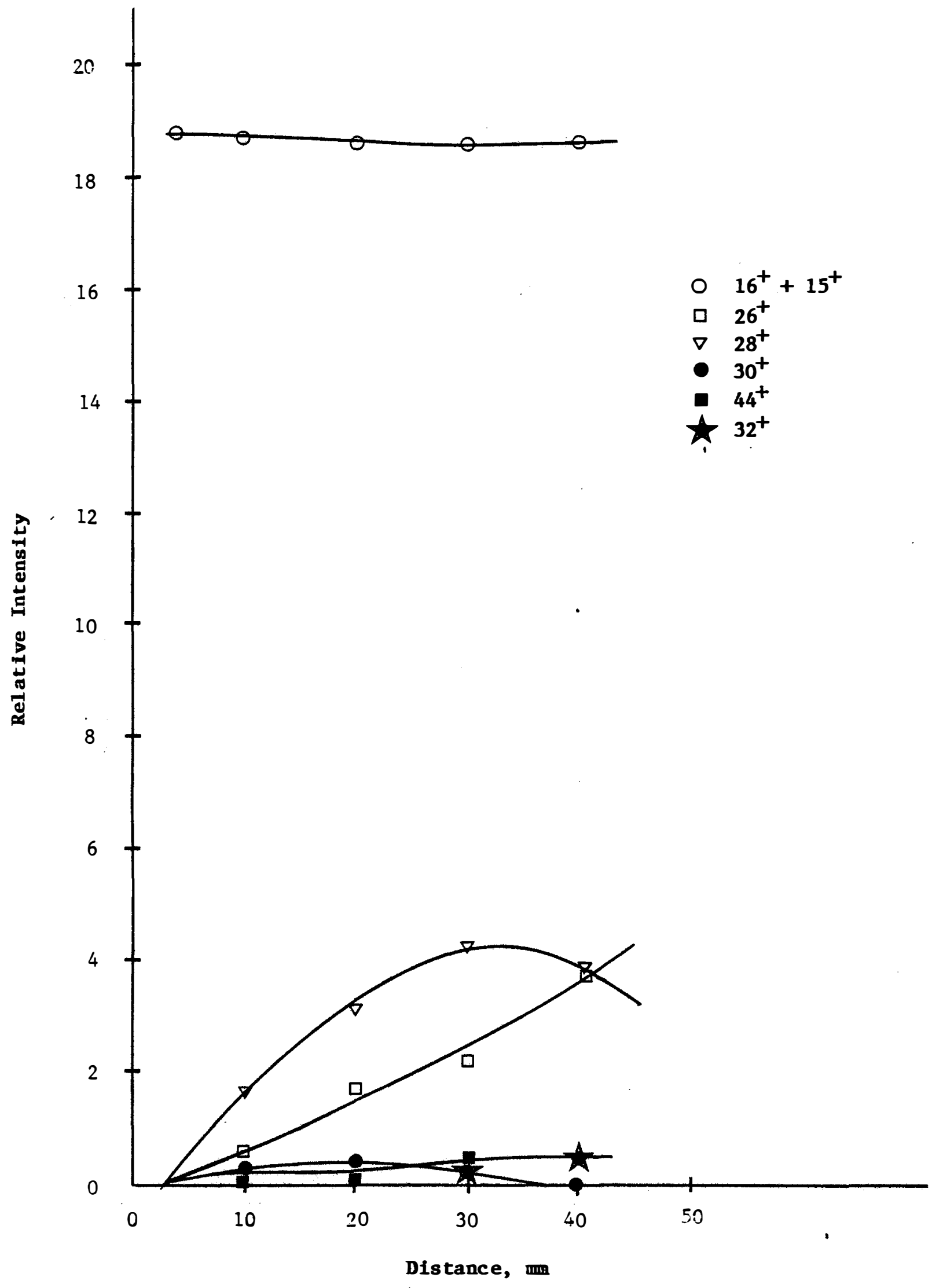

○ $16^{+}+15^{+}$

ㅁ $26^{+}$

$\nabla 28^{+}$

- $30^{+}$

- $44^{+}$

† $32^{+}$

Figure 32. Cracking of $\mathrm{CH}_{4}$ Injected Just Above the Reaction Zone of a $\mathrm{B}_{2}-\mathrm{O}_{2}$-Ar Flame 


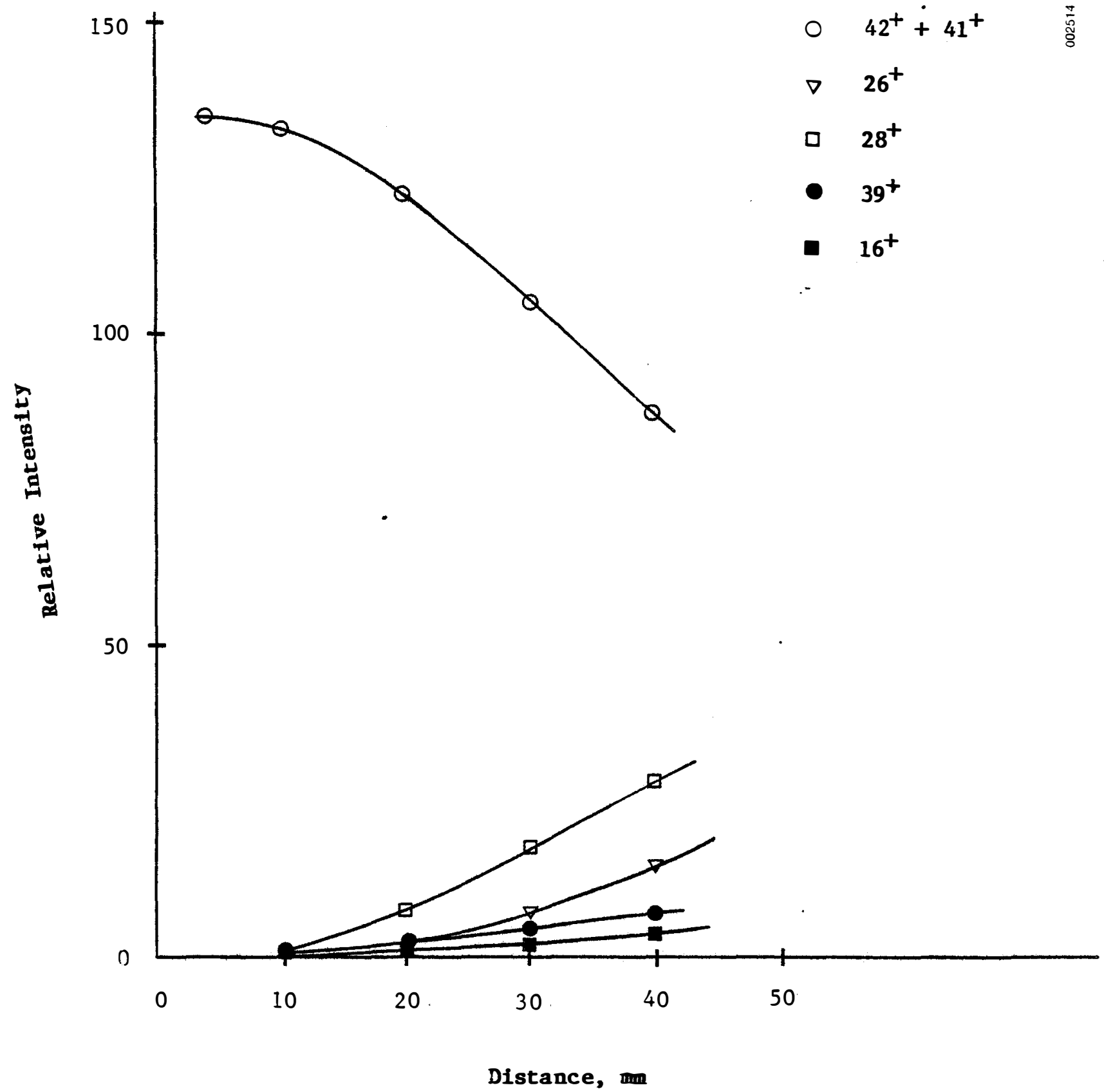

Figure 33. Cracking of Propylene Injected Just Above the Reaction Zone of ; $\mathrm{B}_{2}-\mathrm{O}_{2}-\mathrm{Ar}$ Flame 
Quantitative Calibration for Product Species

Initial attempts have been made to determine relative calibration factors for the important pyrolysis products detected by the mass spectrometer. This task is complicated by the use of low electron energy, which is necessary to limit fragmentation. However, this makes reproducible conditions essential since a small charge in eleçtron energy at $18 \mathrm{eV}$ can make a large difference in the relative intensities of different species.

Calibration factors for several gases relative to $\mathrm{CO}_{2}$ were determined by bleeding binary mixtures through the central tube of the burner chamber. Relative responses varied with flow rates and with distance from the burner to the sampling orifice, but the importance of these factors is still not certain. Tentative relative response factors for several gases relative to $\mathrm{CO}_{2}$ have been calculated: $\mathrm{CO}_{2}=1.00$, $\mathrm{CH}_{4}=0.06 t .01, \quad \mathrm{C}_{2} \mathrm{H}_{2}=2.91 t .38, \quad \mathrm{CO}=0.26 t .05, \quad \mathrm{C}_{2} \mathrm{H}_{4}=2.59 t .23$, $\mathrm{C}_{2} \mathrm{H}_{6}=0.58 t .23, \mathrm{C}_{3} \mathrm{H}_{6}=14.41+3.32, \mathrm{C}_{4} \mathrm{H}_{8}=10.15 \mathrm{t} .44$. Confidence intervals were calculated at the $90 \%$ level. Excessive fragmentation was noted for some of these gases even at the low electron energy setting used, which causes some ambiguity in quantitation.

An initial attempt is currently being made to calibrate response factors for the liquid and solid pyrolysis products also. Comparisons are being made to 5 -methyl furfural ( $M W=110)$ because it gives a spectrum of high molecular ion intensity with negligible fragmentation and thus can be compared to other species without any complication due to ambiguous peaks. Ten mg each of 5 -methyl furfural and the substance to be calibrated are placed in a quartz boat and are volatilized on the $900^{\circ} \mathrm{C}$ steam/argon environment. Future work will also be done at lower temperatures to minimize pyrolysis. The molecular ion for each compound is then alternately monitored over the course of volatilization and the total area under the two curves compared to calculate the relative response of the substance of interest. This system allows substances of different volatility to be compared such as methanol and levoglucosan. It also should allow a combined estimate of the effects of the diverse factors that con- 
tribute to the relative intensity of a given peak, such as appearance potential, mass spectometer tuning, and high mass enhancement during the free jet sampling process.

PLANS FOR FY 1983

The directions of the two coordinated tasks in FY 1983 are briefly summarized in this section.

Director's Discretionary Task (R. Evans, T. Milne)

The major goals of this task are the identification of the primary products of cellulose pyrolysis with emphasis on quantitative yields as a function of time and temperature and on the mechanism of formation. There are several initial questions which need to be answered before meaningful quantitative results can be obtained. The contribution of fragment ions (from the ionization process) to the spectra of pyrolysis products must be determined as has already been described in the case of levoglucosan. This work will be extended to other important products. Another initial question that is being addressed is the establishment of a tuning procedure which balances the needs for resolution and non-discrimination over the mass range of interest. The establishment of calibration factors for the pyrolysis products must be accomplished to correct for mass discrimination in the molecular-beam sampling process and to correct for variation in ionization cross sections for pyrolysis products at the low ionization voltages used in this study.

An important part of this investigation is the determination of the kinetics of primary product generation as a function of temperature. This will be accomplished by looking for variations in the relative abundances of primary products with changes in temperature. The existence of competing mechanisms at higher temperatures may increase the usefulness of thermochemical treatments by establishing the time and temperature of optimum production of desired products. The heated grid will be used in this investigation. Also planned is the use of tandem quadrupoles (MS/MS) for positive identification of the primary pyrolysis products. An important part of this effort will be cataloging the spectra of model compounds and 
possible pyrolysis products under the sampling and ionization conditions used in these experiments. The final effort in this project will be the construction of an overall mechanism of cellulose primary pyrolysis based on this quantitative and qualitative work.

Biomass Energy Technology Division Task (M. Soltys, T. Milne)

The major emphasis of our work now is the quantitative measurement of the rates of secondary cracking of the primary products (also quantified) from cellulose, lignin, extractives, and whole wood, with the initial emphasis on cellulose. Such measurements will involve:

a) Measurement of corrected temperatures throughout the gas column, with and without the presence of pyrolyzing substances and with and without the perturbation of extractive sampling.

b) Careful measurement of relative response of the sampling system/mass spectrometer under both low and high ionizing electron energy, and under reproducible mass spectrometer tuning conditions, for high and low masses. This will involve metered gases and liquids under temperature and dispersion conditions simulating those of the actual pyrolysis.

c) Measurement of statistically reproducible mass spectra of pyrolyzing primary products as a function of temperature and time in hot columns of steam-inert gas and inert gas alone.

d) Measurement of cracking of pure compounds identical to, or representative of, primary pyrolysis products (e.g., levoglucosan, acetic acid, phenol).

Such data should have immediate applied usefulness not only in optimizing conditions for production of valuable products such as ethylene and aromatics but in assessing the conditions needed to destroy refractory organic tars and oils (an extension of such studies to oxidative environments would have great relevance to the use of injected $\mathrm{O}_{2}$ to clean up gasifier effluent streams or combustion generated creosotes). 
ACKNOWLEDGEMENTS

The authors would like to acknowledge helpful discussions with Henk Meuzelaar (U. of $U t a h$ ) and collaborative experiments and discus sions with Hans-Rolf Schulten (Fachhockschule Fresenius, Wiesbaden). Gunther Holzer (Colorado School of Mines) provided much assistance in the direct insertion probe-CI work on the HP mass spectrometer. Continued consultation regarding the heated-grid apparatus with Wlllam Peters (MIT) is also appreclated. Dianna Barney is to be thanked for producing the computer-generated and other graphics. Thanks also to Helena Chum and her group for providing the steamexploded aspen lignin. Don Stevens (PNL) has been most helpful as technical monitor. Partial support from the SERI Director's Development Fund is also gratefully acknowledged. 
REFERENCES

1. Milne, T. A., and M. N. Soltys, 1982, Fundamental Pyrolysis Studies: Quarterly Report, October -December, 1981. SERI/PR -234 1537. Solar Energy Research Institute: Golden, CO.

2. Milne, T. A., and M. N. Soltys, 1982, Fundamental Pyrolysis Studies: Quarterly Report, January-March, 1982. SERI/PR-234 1617. Solar Energy Research Institute: Golden, Co.

3. Milne, T. A., and M. N. Soltys, 1982, Fundamental Pyrolysis Studies. SERI/TP-234-1665. Solar Energy Research Institute: Golden, Co.

4. Milne, T. A. and M. N. Soltys, "Direct Mass-Spectrometric Studies of the Pyrolysis of Carbonaceous Fuels. I. A Flame-Pyrolysis, Molecular-Beam Sampling Technique." Accepted for publication in Journal of Analytical and Applied Pyrolysis.

5. Milne, T. A. and M. N. Soltys, "Direct Mass-Spectrometric Studies of the Pyrolysis of Carbonaceous Fuels. II. Qualitative Observations of Primary and Secondary Processes in Biomass." Accepted for publication in Journal of Analytical and Applied Pyrolysis.

6. Fundamentals of Thermochemical Biomass Conversion: An International Conference. Estes Park, C0; 18-22 Oct. 1982.

7. Milne, T. A. and M. N. Soltys, 1982, "The Direct, Mass Spectrometric Study of the Primary and Secondary Pyrolysis Behavior of Biomass and Its Constituents." International Conference on Fundamentals of Thermochemical Biomass Conversion; Estes Park, C0; $18-22$ Oct. 1982. 
8. Evans, Robert J. "Mechanistic Studies of the Pyrolysis of Biomass-Related Oxygenated and Aromatic Compounds." SERI Director's Discretionary Fund Project No. 2704 (1982-83).

9. Hajaligol, M. R., W. A. Peters, J. B. Howard, J. P. Longwell, 1981, "Product Compositions and Kinetics for Rapid Pyrolysis of Cellulose." Proceedings of the Specialists Workshop on the Fast Pyrolysis of Biomass; Copper Mountain, C0; 19-22 Oct. 1980. SERI/CP-622-1096. Solar Energy Research Institute: Golden, C0.

10. Broido, A. and F. J. Kilzer, 1963, Fire Research Abstracts and Reviews. Vol. 5; p. 157.

11. Milne, T. A. and M. N. Soltys, 1981, Fundamental Pyrolysis Studies: Annual Report for Fiscal Year 1981. SERI/PR-234-1454. Solar Energy Research Institute: Golden, CO.

12. Ohnishi, A., E. Takag1, and K. Kato, 1976, "Curie-Point Pyrolysis, Gas-Liquid Chromatography of Xylan." Carbohydrate Research. Vol. 50; p. 275.

13. Meuzelaar, H. L. C., P. G. Kistemaker, and M. A. Posthumus, 1974, Biomed. Mass Spectrum. Vol. 1; p. 312.

14. Schulten, H. -R. and W. Gortz, 1978, "Curle-Point Pyrolysis and Field Ionization Mass Spectrometry of Polysaccharides." Anal. Chem. Vol. 50 (No. 3): p. 428.

15. Hileman, F. D., L. H. Wojcik, J. H. Futrell, and F. N. Einhorn, 1976, "Comparison of the Thermal Degradation Products of $\alpha$ Cellulose and Douglas Fir Under Inert and Oxidative Environments." Thermal Uses and Properties of Carbohydrates and Lignins. Edited by F. Shafizadeh, K. Sarkanen, and D. Tillman. Academic Press; p. 49: New York. 
16. Franklin, W. E., 1979, Analyt. Chem. Vol. 51; p. 992.

17. Lincoln, K. A., 1981, "High Radiative Heat Flux Pyrolysis of Thin Biomass." Proceedings of the Specialists Wrorkshop on the Fast Pyrolysis of Biomass; Copper Mountain, C0; $19-22$ Oct. 1980. SERI/CP-622-1096. Solar Energy Research Institute: Golden, CO; pp. $153-63$.

18. Haider, K., B. R. Nagar, C. Salz, H. L. C. Meuzelaar, and J. P. Martin, 1977, "Studies on Soll Humic Compounds, Fungal Melanins and Model Polymers by Pyrolysis Mass-Spectrometry." Soil Organic Matter Studies. Vol. II; pp. 213-19. Intl. Atomic Energy Agency, Vienna.

19. Meuzelaar, H. L. C., J. Haverkamp, and F. D. Hileman, 1982, Pyrolysis Mass Spectrometry of Recent and Fossil Biomaterials. Elsevier Scientific Publishing Company: Amsterdam.

20. Schulten, H.-R. (Universitat Bonn, G.F.R.), 1982, Private communication.

21. Chum, H. (Solar Energy Research Institute, Golden, C0), 1982, Private communication.

22. Asplund, D., 1982, Supplied Finnish peats of two types.

23. Diebold, J. (Solar Energy Research Institute, Golden, C0), 1982, Private communication.

24. Milne, T. A. and M. N. Soltys, 1981, Kinetics and Mechanisms of Fast Pyrolysis: Quarterly Report - January -March 1981. SERI/PR 622-1152. Solar Energy Research Institute: Golden, CO.

25. Milne, T. A. and M. N. Soltys, 1981, Pyrolysis Mechanisms: Quarterly Report - April -June, 1981. SERI/PR-622-1347. Solar Energy Research Institute: Golden, CO. 